\title{
EL DICTADOR, OBJETO NARRATIVO EN EL RECURSO DEL MÉTODO *
}

\author{
Por \\ DOMINGO MILIANI \\ Centro de Estudios Latinoamericanos \\ "Romulo Gallegos", \\ Caracas
}

\section{I.- PARTE TEÓRICA}

\section{1.- JUSTIFICACION}

Estas páginas son el enunciado de una hipótesis de trabajo sobre el dictador como fenómeno semantico, histórico y literario en Hispanoamérica.

De amplia frecuencia histórica y escasa delimitación conceptual, el dictador forma una clase de objetos y es ya numeroso el conjunto de novelas hispanoamericanas que lo involucran.

Para estudiar el dictador como objeto narrativo nos pareció conveniente partir de una delimitación tentativa del concepto ('objeto mental') de dictador y sus implicaciones semánticas. 1

De ningún modo intentamos un estudio politológico del fenómeno. Es campo de otros especialistas y lo respetamos. Aún está por escribir una historia globalizadora de los dictadores hispanoamericanos. Si existiera, habría sido apoyo invalorable para nuestro modestísimo intento, restringido al campo concreto de la novela, donde el fenómeno está expresado y parecería estar convirtiéndose en una suerte de moda o constante narrativa.

\footnotetext{
* Una síntesis de la presente introducción teórica, seguida del anásis de las novelas Yo El Supremo y El recurso del método fue leída como ponencia en un Simposio Internacional de Hispanistas (Budapest, agosto, 1976). El resumen teórico y lo relativo a la novela de Roa Bastos se publicaron en Revista de Crítica Literaria Latinoamericana. Lima, $2^{\circ}$ semestre/1976, No 4, pp. 103-119. Son segmentos de un libro en proceso.

1 Kurt Baldinger define 'objeto mental' como "una abstración de muchas realidades emparentadas entre sí, pero la lista de estas realidades queda, en general, abierta, lo cual impide toda enumeración completa (y por consecuencia, toda definición extensional). $Y$ sin embargo puedo identificar ( = relacionar con el objeto mental) una mesa como 'mesa' a pesar de verla por primera vez". Teoría semántica. Madrid, Alcalá, (Romania), 1970, p. 75).
} 


\section{2.- EL PROBLEMA SEMÁNTICO}

Investigar o, siquiera intentar, la reducción semántica del 'dictador' impone, en primer término, precisarlo dentro de una red onomasiológica específica. En la historiografía hispanoamericana se ha venido utilizando indiferencialmente una vasta polimorfía referida a un mismo objeto mental. Así, a un mismo dictador se aplican designaciones como (dictador), tirano, caudillo, déspota, sátrapa, autócrata, etc. El marcado sentido político del concepto, tan frecuente en la vida cotidiana de nuestros países y de la nación española, quizá inhibió a los lexicógrafos modernos en la explicitación de su carga semántica actual. Por lo demás, el sentido etimológico e histórico de los términos, complica aún más el problema. Esto obliga, pues, a proponer una determinación del objeto específico 'dictador' y a analizar su derivación paradigmática 'dictadura', para entrar luego a observar el objeto en los niveles teórico, semiótico y narratológico.

Para los efectos de esta versión estimamos prudente reducir las oposiciones semánticas a tres designaciones del concepto dictador. Analizamos, pues, dictador, caudillo, y tirano, por ser los de mayor frecuencia en el uso hispanoamericano actual.

\subsection{Tirano/Dictador}

Etimológica e históricamente, estos dos términos remiten a la formación de los estados clásicos griego y latino. El tirano aparece en la polis griega. El dictador es típico en la organización del Estado romano.

Platón y Aristóteles son los primeros "teóricos" que se ocupan del concepto 'tirano'. La expansión del término cubre la Edad Media, las repúblicas renacentistas italianas - donde es estudiado por Maquiaveloy acompaña el desarrollo del absolutismo monárquico europeo.

El tirano en Platón es materia de descripciones evaluativas, emocionales. ${ }^{2}$ En Aristóteles, motiva una amplia reflexión. Este último aporta

2 En La República (Lib. I, diálogo Sócrates/ Trasímaco, sobre la Justicia) dice: “...me refiero al que antes nombraba, es decir, al que disfruta de un gran poder; considérale con atención, si quieres llegar a discernir cuánto más le conviene ser injusto que justo. Y lo conocerás mejor si tu punto de vista se fija en la injusticia extrema, la que hace más feliz al más injusto y más desgraciados a los que padecen la injusticia y son incapaces de cometerla. No otra cosa es la tiranía, que arrebata lo ajeno, furtiva o descaradamente, sin consideración a su carácter sagrado o profano, privado o público, y no llevándose en pequeñas partes, sino en su totalidad". (República. Madrid, Aguilar (Joya), Trad. de José Antonio Míguez, 1959; Lib I, VI, 344, pp. 92-93).

En el libro VIII caracteriza al sujeto 'tirano' en tanto "protector del pueblo", como “... aquel que teniendo a su cargo una multitud fácilmente sumisa, no perdona la sangre de su misma raza, sino que, levantando falsas acusaciones, como suele suceder, lleva a sus adversarios a los tribunales y se mancha de sangre en ellos inmolando sus vidas y gustando de la misma sangre de su linaje con su boca y su lengua impuras. Su labor se cifra en desterrar y 
algunos rasgos caracterizadores de importancia. ${ }^{3}$ Algunos llegarán a ser comunes también al dictador. Los más relevantes, para efectos de nuestra hipótesis, son:

a) La tiranía es una desviación de la monarquía.

b) Los tiranos ejercen el poder en provecho particular y no social.

c) Dentro de las tiranías el poder no reside en la ley sino en el gobernante. ${ }^{4}$

Esta demarcación de tirano mantuvo su sentido hasta el escolasticismo y el tomismo, cuando se amplió y aportó bases a los lexicógrafos modernos para describirlo como un adjetivo atribuible a "quien obtiene contra derecho el gobierno de un Estado y a quien lo rige sin justicia y a medida de su voluntad". 5

matar y en proponer el perdón de las deudas y el reparto de las tierras, por lo que no es extraño deba perecer a manos de sus enemigos, o convertirse en tirano... "(lbid, Lib. VIII, XVI, 566, p. 560)

3 Un pormenorizado estudio sobre la La tiranía en Aristóteles. Su examen histórico. (Mérida, Venezuela, Universidad de Los Andes, 1968, fue publicado por Rosa Amaral de Lippolis, en versión offset.

4 Los rasgos anteriores están referidos por Aristóteles en la Política, en la siguiente forma:

a) Distingue entre regímenes rectos (que se proponen el bien común desde el punto de vista de la justicia absoluta), "...y los que sólo tienen en cuenta el de los gobernantes son defectuosos y todos ellos desviaciones de los regímenes rectos, pues son despóticos y la ciudad es una comunidad de hombres libres". (Política. Madrid, Instituto de Estudios Políticos, 1951. Ed. bilingüe. Versión esp. de Julián Marías, Lib. III, 6, p. 80).

Los regímenes rectos (monarquía, aristocracia y república) tienen como desviaciones: “... la tiranía de la monarquía, la oligarquía de la aristocracia, la democracia de la república. La tiranía es, efectivamente, una monarquía orientada hacia un interés del monarca..." (Op. cit., Lib. III, 7, p. 81).

b) Este rasgo está implícito en las citas anteriores. Además, cuando establece los tipos de tiranía (monarcas absolutos, aisymnetas y tiranos propiamente dichos), insiste en que "Es necesariamente una tiranía de esta clase (absoluta) la monarquía que ejerce el poder de un modo irresponsable sobre todos, iguales o superiores, en vista de su propio interés y no del de los súbditos: por tanto, contra la voluntad de éstos, porque ningún libre soporta de grado un poder de esta naturaleza". (Lib. VI, 10, p. 185).

c) Este rasgo se perfila cuando habla de los regímenes dinásticos unipersonales: "Otra forma de oligarquía es aquella en que el hijo sucede al padre en las magistraturas. Una cuarta cuando se da la condición últimamente mencionada, y el poder no reside en la ley sino en los gobernantes". (Lib. VI, 5, p. 177).

5 En esta "definición" coinciden el Diccionario de la Real Academia Española, (1970), el Ideológico (1959) de Casares y la Enciclopedia del Idioma, de Martín Alonso, (1958). 
Sintetizando, puede afirmarse que tirano, histórica y semánticamente es un objeto mental atribuido que surge como antinomia de las monarquías y las democracias primitivas. ${ }^{6}$ Es isócrono en la evolución del Estado monárquico, cuyo poder usurpa y por lo cual las revoluciones burguesas de Europa pudieron ser interpretadas como formas de tirania en el sentido aristotélico, puesto que en las democracias a que dan origen, de acuerdo con la visita aristotélica, "el soberano es el pueblo y no la ley".

El dictador (ris) latino, por el contrario, era legal. Recibía el ejercicio extraordinario del poder por delegación de organismos deliberantes (Senado). ${ }^{7}$

En líneas generales parece admisible que dictador y su derivación paradigmática dictadura son conceptos que evolucionan y se perfilan coetáneamente y en antinomia con las democracias burguesas modernas, en las cuales se produce la separación de poderes, concepto opuesto a la concentración de los mismos en un solo individuo. ${ }^{8}$

6 Apartando la idea de tiranía como desviación de la monarquia, en los autores clásicos el concepto se emparenta por oposición con las democracias primitivas. Platón, por ejemplo, sostiene en dos lugares este criterio:

1) - "Veamos, pues, mi querido amigo, cuál es el origen de la tiranía. Parece claro, por lo pronto, que procede de la democracia". (República, Lib. VIII, XIV, 562, pp. 550-551).

2) En un pasaje, casi inmediato del anterior, reafirma:

- "Y, naturalmente - dije yo- la tiranía no tiene como origen más régimen que la democracia; de éste, esto es, de la más desenfrenada libertad surge la mayor y más salvaje esclavitud". (Lib. VIII, XV, 564, p. 555).

Aristóteles, al considerar las formas aristocráticas de la democracia, establece la posibilidad de las democracias tiránicas:

"En las democracias, de acuerdo con la ley no hay demagogos, sino que son los mejores ciudadanos los que tienen la preeminencia, pero donde las leyes no tienen la supremacía surgen los demagogos. Pues el pueblo se convierte en monarca, constituyendo uno con muchos, porque los muchos tienen el poder, no como individuos, sino en conjunto. (...) Un pueblo así, como monarca, trata de ejercer el poder monárquico no obedeciendo a la ley, y se convierte en un déspota, de modo que los aduladores son honrados, y esta clase de democracia es, respecto de las demás, lo que la tiranía entre las monarquías. Por eso el espíritu de ambos regímenes es el mismo, y ambos ejercen un poder despótico sobre los mejores, los decretos del pueblo son como los edictos del tirano, y el demagogo y el adulador son una y la misma cosa; unos y otros son los más poderosos en sus regímenes respectivos, los aduladores con los tiranos, y los demagogos con los pueblos de esa condición". (Politica. Lib. VI, 4, p. 176).

7 Carl Schmitt ha estudiado detalladamente la evolución histórica de este tipo de dictador que él, siguiendo a Bodino, llama comisario y que llega hasta la Edad Media - cuando se debilita con los comisarios papales - para reaparecer en Alemania con Wallenstein, primer perfil de un dictador moderno. (C. Schmitt, La dictadura. Madrid: Revista de Occidente, 1968). En América, el prototipo de dictador-comisario será el Doctor Francia, durante la etapa genética de su dictadura, bajo forma de Consulado, hasta 1816.

8 En Europa, dentro del pensamiento de la Ilustración aparece el concepto déspota ilustrado, cuya legalidad o ilegalidad es materia de polémica. Schmitt precisa el concepto de despotismo ilustrado pero lo designa como dictadura de la razón, en cuyo sistema se llega a abolir la separación de poderes mediante su concentración absoluta e individual. (Cf. Op. cit, cap. 3, pp.47-ss). La evolución posterior de este tipo de dictadura será la que Schmitt y otros autores designen como soberana o suprema, al modo de José Gaspar Francia en el Paraguay. 


\subsection{Caudillo/dictador.}

El concepto de caudillo es más moderno en el tiempo. En nuestra lengua, su aparición data del siglo XV: caudillo. Designó desde entonces a un sujeto "que guía y manda la gente de guerra", aunque también se aplicaba a un "jefe o director de algún gremio, comunidad o cuerpo". 9

De tal caracterización se desprende que el caudillo ejercita la autoridad, pero no el poder, que no detenta necesariamente.

En España, históricamente, el caudillo es una especie de "relevo" militar de los caballeros medioevales. En América ingresa con los hombres de armas de la Conquista, pero crece y se afianza como rasgo caracterizador de las luchas por la independencia, a tal punto que originó una vasta literatura de la interpretación y la justificación. En ella se ha afirmado que es fenómeno típico de nuestros pueblos o, incluso, que es "original aporte" de Hispanoaménica a las tipologías del asalto contra las democracias. Oportunamente se verá cómo los caudillos no siempre fueron tiranos o dictadores. Al revés, Franco fue designado honoríficamente "Caudillo de todas las Españas".

\subsection{Reducción semántica}

$\mathrm{Si}$ ahora se reduce el campo onomasiológico a las dos oposiciones anteriores generadas por tres términos (la oposición tirano/caudillo no tiene pertinencia en este caso), en sus contrastaciones es posible llegar a una determinación semasiológica (conceptual) de dictador. Los semas de caracterización a que hemos reducido el análisis son los siguientes:

$\mathrm{s} 1$ = (ejercicio del) poder; $\mathrm{s} 2=$ (ejercicio de la) autoridad; $\mathrm{s} 3=$ concentración absoluta (individual); $\mathrm{s} 4$ = legitimidad (concentración legal); s5 = usurpación; s6 carisma.

Los signos (+) y (-) indican la relevancia positiva o negativa del sema para la caracterización del concepto. Cuando un sema es irrelevante (por su indiferencia para la caracterización) puesto que puede o no darse, queda neutralizado (o)

\begin{tabular}{|l|l|l|l|l|l|l|}
\hline CONCEPTOS & $\mathrm{s} 1$ & $\mathrm{~s} 2$ & $\mathrm{~s} 3$ & $\mathrm{~s} 4$ & $\mathrm{~s} 5$ & $\mathrm{~s} 6$ \\
\hline TIRANO $=\mathrm{T}$ & + & - & + & - & + & 0 \\
\hline CAUDILLO $=\mathrm{C}$ & $\mathrm{o}$ & + & + & - & 0 & + \\
\hline DICTADOR $=\mathrm{D}$ & + & - & + & 0 & 0 & 0 \\
\hline
\end{tabular}

9 Casares, Diccionario ideológico, p. 170. Martín Alonso, Enciclopedia del idioma, (éste último repite la definición y la ubica en el s. XV). 
Formulación de los conceptos:

$\mathrm{T}=(\mathrm{s} 1 \mathrm{~s} 3 \mathrm{~s} 5)$

$\mathrm{C}=(\mathrm{s} 2 \mathrm{~s} 3 \mathrm{~s} 6)$

$\mathrm{D}=(\mathrm{s} 1 \mathrm{~s} 3)$

Nota: La intersección se da en $\mathrm{s} 3$. Es el sema de base y también el fundamento de la ambigüedad: sinonímia aparente.

De la reducción se concluye en que el sema o rasgo común donde se apoyan las ambigüedades conceptuales es el de la concentración absoluta (individual) (s3); pero en el caudillo esa concentración es de autoridad (s2), mientras que en el tirano y el dictador es de poder (s1). Entre tirano y caudillo, ahora sí puede anotarse, la diferencia esencial la de usurpación (s5), pertinente en el caso del tirano, neutro en el de dictador. Así, pues, dictador/tirano se homologan en tanto ejercen el poder individualmente, pero no en cuanto a legitimidad o usurpación, ésta última, característica del tirano, pero irrelevante en el caso del dictador. El caudillo ejerce la autoridad local, regional o nacionalmente, pero no requiere, para serlo, el ejercicio del poder; y en caso de ejercerlo, no necesariamente lo hace en forma dictatorial o tiránica.

De lo anterior puede señalarse la conceptuación de dictador como aplicable a:

"quien ejerce el poder en forma individual y absoluta".

\section{3.- EL PROBLEMA TEÓRICO.}

\section{1.-Dictador/dictadura, antonomia ideológica.}

Si bien la determinación conceptual (semasiológica) de dictador es suficiente desde el punto de vista semántico, no lo es en lo político y el problema se remite, por su naturaleza, más a este campo. ${ }^{10}$

El concepto dictador está referido a una individualidad adjetivamente. $\mathrm{Su}$ derivación paradigmática dictadura, en lo político forma parte de un conjunto (clase de objetos) más amplio: la estructura del Estado.

10 Prefiero hablar de insuficiente en lo politico y no en lo ideológico, mientras se procura aclarar la ambigüedad suscitada por el segundo término. Apoyo, además, el planteamiento, en las teorizaciones de Luis Jorge Prieto sobre conocimiento objetivo y conocimiento naturalizado, según el cual todo conocimiento del objeto se inscribe más en el punto de vista del sujeto cognoscente que en "la realidad" del objeto mismo, en especial cuando se trata, como en nuestro caso, de un objeto conceptual. Más adelante se insiste en tales postulados. (Cf. Luis Jorge Prieto: "Pertinencia e ideología". (Trad. Diana Galak, revisión Mario Urriaga. En.. La palabra y el hombre. Xapapa, Veracruz, México, en-mar 1976, N$^{\circ} 17$, pp. 6-20). 
Para la clarificación de este último fenómeno, el marxismo aporta aquí un instrumento fundamental de tipo comprensivo, útil para el estudio particular de la realización hispanoamericana de las dictaduras, donde el corpus macabro que engendra la dicotomía dictador/dictadura es de una exuberancia asombrosa.

\subsection{Engels y la teoría del Estado.}

En 1884, Federico Engels desarrolló su teoría del Estado, para conceptuarlo como una fuerza que brota de la sociedad, pero que se sitúa por encima de ella, y se le hace cada vez más extraño. ${ }^{11}$ Queda aquí, al margen, la polémica sobre si ese por encima de, corresponde al discutido concepto de super-estructura. Importa, en cambio, señalar que al situarse por encima de la sociedad, en tanto se hace cada vez más extraño, se está alejando o divorciando del contexto social donde se origina. Entonces se convierte en instrumento represivo de clase, en las sociedades donde la lucha de clases persiste.

El segundo postulado de Engels, que en realidad antecede al que acabamos de apuntar, precisa:

... el Estado no es de ningún modo un poder exteriormente impuesto a la sociedad; tampoco es la realización de la idea moral, "ni la imagen y la realización de la razon", como lo pretende Hegel. Es más bien un producto de la sociedad cuando llega a un grado de desarrollo determinado; es la confesión de que esa sociedad se pone en una irremediable contradicción consigo misma, y está dividida por antagonismos irreconciliables, que es impotente para conjurar. Pero a fin de que las clases antagonistas de opuestos intereses económicos no se consuman a sí mismas y a la sociedad con luchas estériles, hácese necesario un poder que domine ostensiblemente a la sociedad y se encargue de dirimir el conflicto o mantenerlo dentro de los límites del "orden". 12

Así, el Estado es un instrumento de la sociedad cuando se impone como apremio la tarea de regular la lucha de clases. Lenin, al glosar estas ideas, comenta que "Si el Estado es un producto irreconciliable de las contradicciones de clase, si es una fuerza que está por encima de la sociedad y 'que se divorcia más y más de la sociedad', resulta evidente que la liberación de la clase oprimida es imposible, no sólo sin una revolución violenta, sino también sin la destrucción del aparato del poder estatal que ha sido creado por la clase dominante y en la que toma cuerpo aquel divorcio. ${ }^{13}$

11 Federico Engels, El origen de la familia, de la propiedad privada y del Estado. (Buenos Aires: Claridad, 1946), p. 196.

$12 \mathrm{Ibid}$, p. 195

13 V.I. Lenin, El Estado y la revolución. (Moscú: Ediciones en Lenguas Extranjeras, s.a.), p. 10. 
El Estado es, pues, una forma instrumental, una construcción que ideologiza el dominio de una clase y que se genera por las contradicciones de las clases en el seno de la sociedad. ${ }^{14}$

Marx y Engels, en trabajos anteriores (La Comuna de Paris, Las luchas de clases en Francia, etc.,) habían teorizado sobre el aislamiento respecto de la sociedad, especialmente en ciertas modalidades del Estado moderno, lo que se ha llamado el bonapartismo del Estado. ${ }^{15}$ Esto se traduce en los actuales Estados que se definen como policlasistas, generados por una convergencia accidental y momentánea de intereses de diversos sectores pertenecientes a distintas clases, pero opuestos a otros sectores de esas mismas clases, en cuyo caso estos últimos resultan dominados por la estructura de poder. En tal aislamiento sectorizado, en tal autonomía relativa, se halla una rica posibilidad para comprender al dictador como fenómeno de poder ejercido individual y absolutamente, lo cual es cualitativamente distinto al proceso de las dictaduras de clase.

\section{3.- El axioma de Lenin. La antinomia dictadura/democracia}

Luego de la exterminación del absolutismo monárquico y del surgimiento de las repúblicas burguesas, en el Estado moderno aflora una dualidad de estructuras de poder: democracia/dictadura. Esta relación dicotómica no es alterada en sus términos - aunque sí en su sentido y en sus relaciones sociales- por la aparición del Estado socialista.

Apenas a un año de la toma del poder por los soviets, Vladimir Lenin polemizaba con Karl Kautski y otros socialdemócratas. Enunciaba allí la relación de oposiciones entre dictadura/democracia, que nos ha parecido calificable como un axioma político. Por lo menos en tres textos datados entre 1918 y 1920 , Lenin enuncia e insiste en sus planteamientos. ${ }^{16}$

14 Este carácter instrumental del Estado (instrumental de una clase dominante) curiosamente lo expone Aristóteles, en cuyo enunciado nos parece ver una explícita referencia al proceso de ideologización de la lucha de clases: "(...) Además, como se producen disensiones y luchas entre el pueblo y los ricos, aquellos que más dominan a sus contrarios no establecen un régimen común ni igual para todos, sino que consideran como el premio de su victoria su propio predominio en el gobierno, y unos establecen una democracia y otros una oligarquía". (Politica, Lib. VI, 11, p. 189).

15 Engels admitía que hay momentos históricos “... en que las clases en lucha están tan bien equilibradas, que el poder del Estado, como mediador aparente, adquiere cierta independencia momentánea, respecto a una y otra". (El origen de la familia ..., p. 198).

Lenin glosa estas ideas y las remite a la monarquía absolutista de los siglos XVII y XVIII, al bonapartismo del primero y segundo imperios en Francia y al régimen de Bismarck en Alemania". (Cf. El Estado y la revolución, p. 15.)

16 En realidad El Estado y la Revolución, se sabe que estaba escrito desde antes (1917). Pero los textos polémicos son: "Sobre la democracia y la dictadura" (dic. de 1918), publicado en Pravda, 3 de enero de 1919. En él rebate a Kautzki y Scheideman, partidarios de la "democracia pura" de la burguesía. El segundo trabajo es su famoso Tesis e informe sobre la 
Retomando los puntos de vista de Engels, Lenin comienza por sostener que el Estado es una máquina de opresión de una clase por otra. ${ }^{17}$ En consecuencia, dentro de las sociedades divididas en clases, toda democracia de clase es una dictadura contra las clases opuestas. De igual manera, el sentido de la democracia sólo se realiza como praxis entre los miembros de la clase que detenta el poder. ${ }^{18} \mathrm{De}$ ahí que la democracia burguesa pueda concebirse como una dictadura contra las demás clases - proletariado, campesinado, pequeña burguesía - ${ }^{19} \mathrm{y}$ su apariencia de sistema policlasista queda puesto de relieve. Por otra parte, el concepto de democracia "pura" que los socialdemócratas alemanes defendían - y aún ciertos socialistas de nuestro tiempo exhortan, no sabemos por qué razones estratégicas- no pasaba de ser una entelequia. De modo similar, la dictadura del proletariado - etapa inicial del poder revolucionario socialista- es ejercida contra la burguesía y contra los sectores opuestos a la revolución, mientras subsistan, pero se realiza como una democracia para el proletariado y los sectores identificados con el proceso revolucionario. Esto no significa, en ningún sentido, que se trate de homologar mecánicamente la dictadura del proletariado con las demás formas de dictadura, sino que intentamos señalar las relaciones funcionales ideologizadas (ocultadas).

democracia burguesa y la dictadura del proletariado, presentado al I Congreso de la Internacional Comunista, publicado en alemán (1920) y luego en ruso (1921). Fue recogido en Pravda, 6 de marzo de 1921, No 51. Ambos desarrollos están expuestos en El Estado y la revolución.

17 "Hablar de democracia pura, de democracia en general, de igualdad, de libertad, de espíritu popular, cuando los obreros y todos los trabajadores están hambrientos, desnudos, arruinados, torturados, no sólo por la esclavitud asalariada capitalista (...) mientras los capitalistas continúan poseyendo la 'propiedad' robada y el aparato 'existente' del poder del Estado, es burlarse de los trabajadores y de los explotados. Eso se da de coces con los axiomas del marxismo, que enseña a los obreros: debeis utilizar la democracia burguesa, inmenso progreso histórico en comparación con el feudalismo, pero no olvideis ni un solo instante el carácter burgués de esa 'democracia', su carácter históricamente condicionado y limitado, no compartais la 'fe supersticiosa' en el 'Estado'; no olvidéis que incluso en la república más democrática, y no sólo en las monarquías, el Estado no es sino una máquina de opresión de una clase por otra". (Sobre la democracia y la dictadura. Moscú: Ediciones en Lenguas Extranjeras, s.a., p. 12).

18 "La burguesía se ve obligada a mentir hipócritamente y a llamar 'Poder popular' democracia en general o democracia pura a la república democrática (burguesa, que es, de hecho, la dictadura de los explotadores sobre las masas trabajadoras. (...) la república democrática, la Asamblea Constituyente, las elecciones populares, etc., son la dictadura de la burguesía, y para liberar al trabajo de la opresión del capital, no hay más camino que la sustitución de esa dictadura por la dictadura del proletariado". (Ibid., pp. 12-13).

19 “... en toda sociedad capitalista únicamente pueden tener importancia decisiva la burguesía o el proletariado, y los pequeños propietarios son inevitablemente vacilantes, impotentes y necios soñadores, que aspiran a la democracia 'pura', es decir, a la democracia al margen de las clases o por encima de ellas. Porque de una sociedad en que una clase oprime a otra no se puede salir si no es mediante la dictadura de la clase oprimida". (Ibid., p.p. 14-15). 
Lenin aclara muy bien el problema. Las democracias burguesas llevan al ejercicio efectivo del poder a una minoría dominante, contra una mayoría dominada por la dictadura burguesa oculta en esa democracia. En la dictadura del proletariado los términos se invierten, en tanto que son las mayorías sociales las que participan en una democracia y ejercen la dictadura contra una minoría históricamente explotadora. ${ }^{19 a}$

En Hispanoamérica, esta relación antinómica se ha venido expresando en un juego de relaciones paradigmáticas (opositivas). Exteriorizan la ambigüedad no sólo semántica sino de praxis represiva contra la cual el humor popular establece otra relación posible: dictadura/dictablanda. Es decir, democracias en apariencia, pero dictaduras en las ejecutorias, o bien, dictaduras blandas, en oposición a democracias duras.

\section{4.- TIRANOS, CAUDILlOS, DICTADORES Y DEMOCRACIAS EN HISPANOA- MERICA}

Las designaciones tirano, caudillo, dictador, dijimos que han funcionado como sinónimos en el uso político hispanoamericano. A veces han denominado un mismo caso particular (sujeto) de gobernante. Su ambigüedad semántica se proyecta a todas las épocas históricas del Continente, aunque en el siglo XX se ha venido imponiendo la designación englobante de dictador.

En la época de colonización española se utilizó tirano para designar a algunos conquistadores que desconocían la autoridad metropolitana del rey y ejercían su poder regionalmente. El más célebre fue $E l$ Tirano Lope de Aguirre. Algunos historiadores ven en ellos el ancestro de nuestros caudillos. Durante las luchas emancipadoras, Bolívar utilizó el término tirano y su derivación tiranía para aludir reiteradamente al poder opresivo colonial, pero también lo aplicó para referirse a José Gaspar Rodríguez de

19a "La dictadura del proletariado tiene de común con la dictadura de las otras clases el que está motivada, como toda otra dictadura, por la necesidad de aplastar por la fuerza la resistencia de la clase que pierde la dominación política. La diferencia radical entre la dictadura del proletariado y la dictadura de las otras clases $-\ldots-$ consiste en que la dictadura de los terratenientes y de la burguesía ha sido el aplastamiento por la violencia de la resistencia ofrecida por la inmensa mayoría de la población, concretamente por los trabajadores. La dictadura del proletariado, por el contrario, es el aplastamiento por la violencia de la resistencia que ofrecen los explotadores, es decir, la minoría ínfima de la población, los terratenientes y los capitalistas".

De aquí dimana, a su vez, que la dictadura del proletariado no sólo debía traer consigo, inevitablemente, el cambio de las formas y de las instituciones de la democracia, hablando en general, sino precisamente un cambio que diese una extensión sin precedentes en el mundo al goce efectivo de la democracia por los hombres que el capitalismo oprimiera, por las clases trabajadoras". (Tesis e informe sobre la democracia burguesa y la dictadura del proletariado. Moscú: Ediciones en Lenguas Extranjeras, s.a., pp. 29-30). 
Francia. ${ }^{20}$ San Martín, por la misma época, se lamentaba de que lo llamaban tirano, de lo cual estaba cansado. ${ }^{21}$

Las luchas de emancipación promovidas contra España produjeron caudillos que ejercían carismáticamente la autoridad regional, lo mismo al servicio del imperio que de la causa republicana. Muchos cambiaron de bando. Los del lado patriota terminaron exaltados como héroes libertadores, pero no todos llegaron a ejercer el poder nacional. En el período de la organización republicana, los caudillos protagonizaron las guerras civiles en lucha por el control individual del Estado. Son las llamadas "revoluciones" que tienen en ellos a sus agentes principales. Las actitudes y convicciones políticas de algunos caudillos estuvieron del lado de los sectores oprimidos por las oligarquías criollas: fueron caudillos populares o buscaron respaldo en sectores del pueblo. Otros llegaron a ejercer el poder, pero no necesariamente en forma dictatorial. Hay quienes distinguen en estos casos, entre caudillos y caciques. ${ }^{22}$ Señalan a los primeros como caciques que alcanzan autoridad nacional y terminan ejerciendo el poder.

20 "Es una cosa positiva que en cuanto nos presentemos en Venezuela se nos agregan valerosos patriotas que suspiran por vernos parecer, para sacudir el yugo de sus tiranos..." ("Memoria dirigida a los ciudadanos de Nueva Granada por Un Caraqueño". (1812) (En: Bolívar. Obras Completas. La Habana: Lex, 1947; t. I., pp. 47-48).

"La Provincia del Paraguay está ocupada por un tal Francia, que la tiene perfectamente cerrada catorce años ha. No pertenece a nadie ni tiene gobierno alguno, sino un tirano que es un enemigo virtual de todo el mundo, porque con nadie trata y a todos persigue..." (Carta a Francisco de Paula Santander. Arequipa, 30 de mayo de 1825. Op. cit, t. II, p. 1106)

21 En carta a O'Higgins, fechada en agosto de 1822, luego de la entrevista de Guayaquil, San Martin se lamenta: "Créame, amigo, estoy cansado de que me llamen tirano, y de que hayan dicho por todas partes que quiero ser rey, emperador, o aun el diablo". (Citada por $\mathrm{H}$. Herring., Evolución histórica de América Latina, Buenos Aires, EUDEBA, 1972, 2 vols. Cita en t. I, p. 309).

22 En la historiografía hispanoamericana es común hallar la utilización caudillo-dictador. Baste, sin embargo, recordar casos como el de Yegros (caudillo legítimo del Paraguay) y el dictador Francia para observar cómo éste, sin ser caudillo, habiendo permanecido casi al margen del proceso emancipador, se erige dictador por sobre la voluntad y el carisma del primero y oprime al Paraguay durante 25 años. Caudillos fueron tanto el realista José Tomás Boves, como los patriotas Santiago Mariño, Manuel Piar, etc.; todos participaron en la lucha emancipadora en uno u otro bando, pero no ejercieron el poder. Emiliano Zapata, en el siglo $\mathrm{XX}$ es típico caudillo agrarista popular y no fue gobernante.

En el aspecto técnico de léxico, Francois Chevalier estima que la aparición del caudillo en América se debe a o es consecuencia de un vacío de poder generado por la desaparición del Estado español. Los caudillos aparecen ligados al fenómeno del machismo. Se imponían a los demás por el terror, pero no todos ellos llegaron al poder.

La distinción caudillo/cacique ha sido estudiada por el historiador mexicano Moisés González Navarro, en cuya tipología apoya su trabajo el colombiano Fernando Díaz Díaz (Caudillos y caciques. México: El Colegio de México, 1972).

El cuadro de paralelismos y oposiciones caudillo/cacique, propuesto por estos dos historiadores es el siguiente: 
La antinomia democracia/dictadura es una larga fluctuación de estructuras del Estado que arranca desde la organización republicana y llega a nuestros días en oscilación irónica ya apuntada: dictadura/ dictablanda, para reformular dramáticamente la necesidad de transformar definitivamente ambas estructuras-instrumentos de burguesias "transnacionales". Democracia y dictadura han sido, pues, en Hispanoamérica, dos instrumentos alternos de dominación neo-colonial. Ha habido, por lo demás, casos de dictadores nacionalistas y anti-imperialistas, más consecuentes con los intereses nacionales - aunque no siempre con las mayorías populares - y ha habido democracias "representativas" cuyo poder de entrega a las metrópolis y cuyas ejecutorias represivas (democracias-duras) contra las mayorías sociales han hecho palidecer a sanguinarios dictadores o han generado por contraste la ironía aplicada a dictaduras menos sádicas: (dicta-blandas).

La nueva metrópoli imperialista ha jugado cíclicamente con ambas formas instrumentales para ejercer su dominación más o menos disimulada.

De otra parte, el dictador, como objeto expresivo de aislamiento "momentáneo" del poder respecto a las clases sociales, no siempre ha sido militar como el caudillo, (aunque también se habla de caudillos civiles). Y hemos tenido dictadores civiles mucho más represivos que numerosos

Paralelismos: a) búsqueda de dominación en un grupo social determinado, fundada en la costumbre, en la tradición o el carisma. b) Alcance de la dominación por: 1) oportunismos (político, militar, religioso); 2) medios económicos; 3) cualidades personales (valor, audacia, inteligencia, machismo, etc.); 4) clientela numerosa (grupos desposeídos, familiares, amigos); 5) apoyo en una bandería o partido. c) Apoyan su poder en un séquito de prebendados. d) Uso del poder en provecho personal. e) Explotación de su condición necesaria en casos de emergencia nacional. f) Justificación legal de la usurpación sobre el argumento de defensa del orden. g) Mesianismo. Fe en la tarea que ejercen.

Oposiciones: (diferencias) (según González Navarro, cit. por Díaz Díaz): Caudillo:

a) Mentalidad urbana

b) Lucha por el cambio social

c) Un programa

d) Tránsito del carisma a la legalidad

Cacique:

a) Proyección regional

b) Defensa del statu quo

c) Una jacquerie (sublevación campesina ?)

d) Tránsito del carisma a la dominación tradicional

Nota: El texto amplio de estas relaciones, en Díaz Díaz, op. cit., pp. 3-4.

Nótese que hay confusiones en las identificaciones y diferencias entre caudillo/dictador, así como en cacique/caudillo. No es para detenerse ahora en el problema, pero sí queríamos ratificar nuestro planteamiento de 2.2. e insistir en la idea de caudillo ejerce una autoridad regional que puede extenderse al ámbito nacional sin llegar al poder. En lo primero se identificaría con el cacique, más no en cuanto al ejercicio de poder. 
militares reformistas y populares. En los últimos años, sobre todo, se han observado fenómenos de populismo militar e incluso, de tentativas militares cuyos contenidos revolucionarios por momentos han tratado de acercarse al socialismo, aunque por vías diferentes, como el llamado "humanismo revolucionario" peruano. ${ }^{23}$

El dictador hispanoamericano no siempre ha llegado al poder por usurpación o transgresión de los instrumentos jurídicos del Estado, sino mediante esos mismos instrumentos jurídicos a los cuales apela en ocasiones: constitucionalidad, sufragio, defensa del orden, etc. Es más: la mayoría de estos tipos ha ideologizado sus ejecutorias dictatoriales mediante la conservación aparente de los demás poderes: parlamento, poder judicial. Muchos han hecho ostentación del "respeto a las sagradas leyes de la patria" o se autodesignan "restauradores de las leyes y el orden". Así, la diferenciación con los tiranos, además de histórica se propone ser jurídica.

En torno a la respuesta de clase, los dictadores forman un entorno de poder con sectores de clases sociales diversas y aun antagónicas como tales, durante lapsos distintos, en una sola prolongación de su mandato. En sus actuaciones, generalmente muy extensas y hasta perpetuas, el apoyo social recibido ha fluctuado en lo nacional, pero ha sido continua la mediatización del imperialismo. Un mismo sujeto dictatorial se ha recubierto a veces como liberal, conservador, radical, burgués, populista, fascista. En los especímenes dictatoriales, sin embargo, se ha mantenido constante un rasgo, más allá de la apariencia de legalidad con que han pretendido ideologizar sus gobiernos; ese rasgo constante es: la concentración absoluta (individual) y abusadora del poder.

\section{EL DICTADOR, OBJETO SEMIÓTICO.}

Centramos ahora la conceptuación del dictador en otro nivel que quizá permita comprender por qué hemos designado esta especie de poder individual como un objeto.

Max Bense delimita el concepto de objeto semiótico, así:

... todo aquello que puede ser percibido, reconocido o pensado como tal, y finalmente puede ser representado por medio de un signo, o presentado, o

23 Esta denominación nace de los trabajos teóricos escritos por el filósofo peruano Francisco Miró Quesada, que han servido de base doctrinaria al proceso vivido en los últimos años por su país. (Cf. especialmente: Humanismo y revolución. La segunda edición ampliada de esta obra, circulará este mismo año, editada por el Centro de Estudios Latinoamericanos "Rómulo Gallegos", Col. Repertorio Americano). 
también designado, es un objeto. El concepto abarca tanto a los objetos reales del mundo exterior como a los objetos ideales de la conciencia. 24

El mismo Bense cita a Peirce para fijar el concepto de objeto dinámico, en el sentido de "objeto designado, que está dado realmente de un modo u otro, que es accesible a la percepción y que ocasiona la formación de signos." 25 Dentro de los objetos dinámicos establece la sub-clase de objetos abstractivos, como aquellos que designan cualidades (atribuciones). Pensamos que sobre estas bases teóricas puede fijarse el concepto de dictador como objeto dinámico - abstractivo, de acuerdo con el desarrollo que estamos intentando.

Abraham Moles ha pormenorizado una serie de categorías sobre el objeto (en nuestro caso objeto-dinámico-abstractivo) que permite precisar más el objeto dictador como tal. Estimamos que él fija las bases para diferenciar los objetos conceptuales de los objetos concretos. Su planteamiento comprensivo lo lleva a la siguiente afirmación:

La noción misma de objeto está unida a una semiótica puesto que el objeto es manipulado conceptualmente a partir del nombre que sirve para designarlo; esto corresponde en general a la idea de segmentación, de aislamiento y de movilidad de lo observado respecto de un marco, es decir, de hecho, a los universales de Aristóteles. El nombre es ya una primera generalización, puesto que por su plural - "casas", "árboles", "ceniceros" - admite a priori la existencia de un gran número de elementos idénticos agrupados bajo el mismo nombre. 26

En el caso del dictador, ocurre, sin embargo, que no se trata de objetos idénticos - "dictadores" - y, por tanto, es una clase heterogénea, sólo identificable como generalización en un nivel abstractivo. El dictador es manipulable conceptualmente, sin duda, pero con la advertencia de que no permite esa calificación de que todos los dictadores son "idénticos". Creemos que en el nivel conceptual tampoco se da el caso de objetos idénticos sino por abstracción sémica, donde la determinación de los semas constitutivos diferenciales - respecto de otros objetos: tiranos, caudillos, etc. - permite una abstracción unívoca, en la medida en que son semas de base, comunes a una clase objetual.

El conocimiento del objeto, por lo demás, según Luis Jorge Prieto,

24 Max Bense y Elizabeth Walther. La semiótica. Guia alfabética. (Barcelona: Anagrama, 1975), p. 113.

25 Ibid, p. 115.

26 Abraham Moles. "Objeto y comunicación". (En: Moles y otros. Los objetos. Buenos Aires: Tiempo Contemporáneo. Comunicaciones 13, 1971, p. 9). 
señala hacia el punto de vista del sujeto que percibe y produce el concepto para concluir designándolo (identificándolo). ${ }^{27}$

En el caso del objeto dictador, las observaciones de Prieto cobran una importancia especial, pues se trata, como veremos, de un objeto conceptual atribuido por el sujeto conoscente (padeciente, sería más justo) a otro sujeto que, como emisor, en la comunicación social de los dictadores, niega su carácter de tal. Ya el problema no es que la conceptuación sea o no verdadera sino que el sujeto - $\mathrm{y}$ en general los sectores dominados por un dictador- identifiquen el objeto de referencia. Cito de nuevo a este propósito la observación de Prieto sobre "Concepto y verdad":

La identidad bajo la cual un sujeto conoce un objeto material es, ciertamente, la manera en que lo concibe: conocer un objeto bajo cierta identidad es en definitiva reconocerlo como miembro de una clase y, en consecuencia, como parte de la extensión de un concepto. Esta observación nos permite hacer algunas consideraciones, que nos serán útiles más adelante, a propósito de la "verdad" de un concepto y, por ende, de la identidad de un objeto que resulte de concebirlo a través de ese concepto. (...)

La verdad de un concepto se mide por su grado de adecuación al punto de vista en función del cual se lo considera y del que depende su pertinencia, y no por su adecuación al objeto mismo; es decir, un concepto es más o menos verdadero por su mayor o menor aproximación al ideal de rescatar todo lo que en el objeto sea pertinente en función del punto de vista adoptado y sólo lo que es pertinente en función de ese punto de vista. 28

El objeto, material o conceptual, es un instrumento producido por el hombre. Se inserta en una praxis de la cual depende su filiación como miembro de una clase objetual y porta un mensaje referido a un contexto social. ${ }^{29}$ Además, el objeto es un mediador de la relación entre el hombre y

27 Luis J. Prieto. "Pertenencia e ideología" (v. nota 10). El gran investigador argentino reitera la idea en dos momentos de su ensayo: 1) "el problema de la identidad bajo la cual el sujeto parlante conoce los sonidos de la lengua se plantea, en general, a propósito de la identidad bajo la cual un sujeto conoce un objeto material cualquiera, cuando en realidad la pertinencia de las características que determinan tal identidad no tiene su fundamento en el objeto mismo; por otro lado, como en el caso de los sonidos, es en función del punto de vista determinado desde el cual el sujeto considera el objeto, que se explica siempre esta pertinencia". (p. 8). 2) V. nota siguiente.

28 Prieto, loc. cit. p. 9.

29 Omito nuevas transcripciones textuales en el ensayo de Prieto, pero insisto en el hecho de que la experiencia (praxis) de un sujeto social es, en último caso la que da sentido a la atribución del concepto dictador a un determinado gobernante, cuyo conocimiento e identidad está en la clase dictatorial del objeto asi designado. El dictador propiamente dicho, negará su condición de tal, en la mayoría de los casos, y tomará la identificación como un agravio. Su identidad no está, pues, objetivamente dada en el portador material del objeto conceptual (el dictador) sino en quien lo señala y ubica en la clase de objetos conceptuales designados "dictador", es decir, en el sujeto que produce el signo de representación e identificación. 
la sociedad. En este carácter mediador, el objeto configura un entorno del hombre. Así, es a un tiempo mediador y barrera. El entorno del dictador está constituído por un conjunto de individuos que lo respaldan - como clase o como sectores de clases sociales distintos- ; lo apoyan, pero también lo utilizan - lo manipulan - como objeto y lo aíslan del resto de la sociedad. ${ }^{30}$

Si se deja a un lado el problema casuístico de un dictador para observar la clase objetual de 'el dictador', al menos en Hispanoamérica, ésta se forma con un conjunto de objetos producidos socialmente, a distancia de la sociedad y dirigidos a englobarla. Sin embargo, el objeto dictador es un objeto conceptualmente atribuido. El individuo humano en que se actualiza el objeto conceptual del dictador, lo mismo que su entorno (formado por los sectores de apoyo donde figuran grupos imperialistas, sectores de clases, acólitos individuales), no son los productores intelectuales del concepto formado por atributos o rasgos pertinentes a ese objeto abstractivo: dictador. En otras palabras, ni el individuo humano que es dictador, ni sus adictos que forman el entorno, admiten la designación de dictador; por el contrario, tratan de rechazarla, de negarla. Tanto el dictador como su cohorte generan una discursividad verbal, una red de epítetos enfáticos, de eufemismos, que ideologizan (ocultan) la realidad del objeto (dictador). Esa red atributiva magnifica al individuo como gobernante, pero niega la condición dictatorial de su comportamiento. La discursividad ideologizadora se va transfiriendo de los individuos (un dictador en particular) a la clase de objetos (los dictadores) que en conjunto forman continentalmente. Así puede comprobarse con facilidad, aun en un corpus restringido, que ciertos epítetos acuñados para justificar a un dictador, o incluso, atribuidos a figuras nacionales (caudillos $u$ otros) que no lo fueron, terminan por ser lugares comunes asignados a todo el set dictatorial.

30 Resulta de suma utilidad, para la comprensión de nuestro esbozo, el concepto de entorno aportado por Moles: "... esencialmente todo lo que está alrededor de un individuo en el espacio y en el tiempo". (Teoría de los objetos. Barcelona, Gustavo Gili, 1974, p. 12).

Según el mismo autor, el entorno genera una suerte de vacío fenoménico, de distanciamiento social del individuo. "En este vacío social, el fenómeno esencial para el psicólogo pasa a ser el entorno del individuo, especie de 'concha' más o menos cerrada sobre la que se proyectan los mensajes del mundo exterior, mensajes próximos o lejanos, transmitidos por telecomunicación y sobre el cual él actúa a su vez". (Ibid, p. 19). Lo irónico está en que el entorno del dictador está constituido por hombres reificados, por objetos humanos que lo áslan del contexto social, que son manipulados por él y al mismo tiempo pretenden ser manipuladores sociales a distancia. Moles señala que ese entorno objetual del hombre moderno produce, como consecuencia, un aislamiento en el cual "... el hombre se encierra en su propia esfera, pierde el contacto con los otros, pasa del carisma de Weber a la reificación del otro, a la impersonalización funcional de los seres", (p. 20). 
Se podría formar un extenso catálogo de epítetos magnificadores cuya función ideologizadora (ocultadora o negadora del objeto) obra por extensión a la clase. Incluimos apenas una muestra:

\begin{tabular}{|l|l|}
\hline $\begin{array}{l}\text { EPITETOS NEGADORES } \\
\text { (ideologizadores del objeto) }\end{array}$ & $\begin{array}{l}\text { DICTADORES NEGADOS } \\
\text { (Magnificados) }\end{array}$ \\
\hline RESTAURADOR & $\begin{array}{l}\text { Antonio López de Santa Ana (México) } \\
\text { Juan Manuel de Rosas (Argentina) } \\
\text { Cipriano Castro (Venezuela) }\end{array}$ \\
\hline PROTECTOR* & $\begin{array}{l}\text { José de San Martín (Argentina) (?) } \\
\text { José Gervasio Artigas (Uruguay) (?) } \\
\text { Augusto Pinochet (Chile) }\end{array}$ \\
\hline BENEMERITO & $\begin{array}{l}\text { Antonio López de Santa Anna (México) } \\
\text { Juan Vicente Gómez (Venezuela) } \\
\text { Mariano Melgarejo (Bolivia) }\end{array}$ \\
\hline BENEFACTOR & \begin{tabular}{l} 
Rafael Leonidas Trujillo (Rep. Dominicana) \\
\hline
\end{tabular} \\
\hline $\begin{array}{l}\text { (*) Nótese cómo el epíteto de Protector, históricamente procede de dos caudillos (Artigas } \\
\text { y San Martín) y fue adjudicado por un dictador civil (Bordaberry) a uno de los engendros } \\
\text { dictatoriales más sombríos de nuestro tiempo. }\end{array}$ \\
\hline
\end{tabular}

En Hispanoamérica la ideologización del dictador, sea cual fuere la forma como asume el poder absoluto, termina generalmente legalizando su mandato, gracias al respaldo discursivo de ciertos "ideólogos" productores de textos exaltativos del gobernante, claramente marcados por la intención de negar el objeto dictador. Papel relevante jugó en este sentido la pretendida interpretación sociológica "científica" de la realidad hispanoamericana, suscrita por descollantes pensadores positivistas que fueron, además, los cerebros tras los cuales se escamotearon ciertos individuos de la clase dictatorial. 31

31 Entre ellos destacan por su influencia y por la polémica engendrada alrededor de sus textos, por lo menos dos nombres: Francisco García Calderón, autor de Les democraties de l'Amerique Latine (París, 1912), en la cual habla de "tiranos benefactores". El otro es el venezolano Laureano Vallenilla Lanz, cuyo Cesarismo democrático (1919) fue una suerte de catecismo justificador de la dictadura de Juan Vicente Gomez. A tales tesis se han opuesto historiadores posteriores, quienes han salido en defensa de la democracia burguesa. En Venezuela descuella por su calidad y documentación, Augusto Mijares: La interpretación 
Un caso excepcional es José Gaspar Francia, quien no sólo asumió la designación de dictador a conciencia, sino que la ostentó como título honorífico, cuando el Consulado lo invistió con jerarquía de Dictador Supremo. ${ }^{32}$ Estamos así en presencia de una excepción notable dentro del sistema de los epítetos negadores del objeto, aunque magnificadores del individuo.

Por oposición al sistema discursivo de los magnificadores del individuo humano, pero negador del objeto dictador, socialmente se produce otro sistema o contra-sistema integrado por frases denostadoras. Sus productores son - como dijimos antes- los oponentes o víctimas de ciertos dictadores. En su expresión se configura y afirma el objeto dictador. Es la misma praxis opresiva, descargada sobre las víctimas, el contexto de donde surge el objeto conceptual y su expresión verbal.

Este segundo sistema de denostadores-afirmadores del objeto es el que ha dado lugar a la polimorfía de las designaciones dictador, sátrapa, tirano, déspota.

Si el primer sistema de epítetos (magnificadores-negadores) forma parte de un universo discursivo soportado por la oratoria y los ensayos del sujeto dictatorial y su entorno, el segundo contra-sistema produce un universo opuesto, constituido por lexías de escarnio, chistes, además de una rica literatura de protesta que en su lucha contra el individuo dictatorial, identifica y define al objeto: lo afirma. Ambos universos se internacionalizan en lo geográfico y se extienden a todos los individuos de la clase de objetos-dictador.

De todo lo anterior se puede concluir ahora que el objeto semiótico dictador (dinámico-abstractivo) no se corresponde con un individuo concreto (un dictador determinado) en todos sus componentes, menos cuando ese individuo, como emisor de mensajes se niega en su carácter de objeto conceptual. Los atributos que identifican al objeto, tanto como sus

pesimista de la Sociología hispanoamericana. (Caracas: Coop. de Artes Gráficas, 1938). Casi contemporáneos de Vallenilla, fueron sus refutadores: el liberal colombiano Eduardo Santos, quien editorializó en El Tiempo (1920) y el uruguayo Mario Falcao Espaltar, quien escribió en La Prensa de Buenos Aires (1925) contra las tesis del cesarismo.

32 Uno de sus biógrafos, por cierto, destaca que “... los dictadores sólo revelan imaginación para los títulos que tienen que darle una categoría más presidencial. Se llamaron El Fundador (Páez); El Regenerador (Guzmán Blanco); El Rehabilitador (Márquez Bustillos) (sic); El Defensor (Juan José Flores); El Salvador (Cipriano Castro); El Salvador del Salvador (Juan Vicente Gómez) (sic); El Supremo (José Rodríguez de Francia". (Guillermo G. Cabanellas. El Dictador del Paraguay, Doctor Francia. Buenos Aires: Claridad, 1946; nota 3 al pie de p. 195). Ignoramos las fuentes de donde obtuvo Cabanellas los epítetos; en todo caso, sirven para ilustrar y confirmar nuestra exposición. En el caso de Márquez Bustillo, sin embargo, cabría preguntarse si fue en realidad un dictador (¿por sustitución momentánea de Gómez?) y en cuanto al epíteto que lo magnifica, causa un poco de extrañeza, igual que el atribuido a Gómez. 
designaciones se dan, pues, en una clase que es homegénea sólo conceptualmente pero que en la realidad está constituída por objetos físicos diversos (los individuos que se comportan como dictadores particulares). $\mathrm{Si}$ cada individuo tiende a negar su identidad, sólo el conocimiento del objeto conceptual que los engloba permite una definición.

La dualidad de discursividades formada por los epítetos magnificadores (negadores del objeto) y los denostadores (afirmadores del objeto) suponen un universo de discurso cuya riqueza y complejidad sólo puede abarcarse más allá de un solo caso histórico específico. Como sistema de expresión no es localizable singularmente ni en un solo tiempo (un período dictatorial individualizado) ni en una sola espacialidad (un sector geográfico nacional particular).

La discursividad magnificadora provoca el mito del dictador. Dentro de ella se implican los propios exponentes de la retórica del individuo dictatorial y de su entorno (funciones negadoras del objeto). La discursividad denostadora tiende a desmitificar y debelar el verdadero objeto dictatorial. Si el sistema magnificador deviene en una subliteratura de lugares comunes que distorsiona, oculta o niega el objeto dictatorial, el contra-sistema denostador es base de un metalenguage del dictador, que lo hace emerger para definirlo en su sentido conceptual. A este segundo sistema creemos que corresponde la novela del dictador latinoamericano, pero ella es en sí un segundo objeto semiótico narrativo heterogéneo, producido a partir del objeto dinámico abstractivo. Por su misma heterogeneidad de objeto artístico y por el punto de vista desde el cual aborda el primer objeto conceptual del dictador, en la novela del dictador pueden observarse algunas sub-clases.

\section{6.- NOVELAS DE DICTADURAS, NOVELAS DE DICTADORES}

Hemos apuntado que a partir del dictador como objeto semiótico, se producen dos niveles contrapuestos de discursividad. Ambos son intencionales en su heterogeneidad comunicativa, en su oposición respecto a la definición del objeto. Ambos constituyen un repertorio verbal de materiales a partir de los cuales la novela es producida como un segundo objeto semiótico, esta vez un objeto artístico, que es también, por definición, heterogéneo.

Si el dictador se presenta cono un objeto semiótico dinámico abstractivo, que se construye sobre atributos comunes a un conjunto de individuos (homogéneo en tanto conjunto, heterogéneo en cuanto a las particularidades de los individuos que lo integran), su caracterización histórica es una operación diferente a la novelización del objeto. 
El dictador, como objeto abstractivo produce o puede producir novelas que sustancialmente se construyen sobre la atmósfera o situación generada por una dictadura particular, en cuyo caso la discursividad se expande y desvia hacia un contexto social y el objeto narrativo termina por ser un caso particular de las novelas de protesta social contra la dictadura. Esta sub-clase de objeto narrativo aparece en Hispanoamérica desde los primeros años de la organización republicana, si bien la dictadura está esbozada como atmósfera del verdadero objeto narrativo que la articula en su trama: el idilio. Así ocurre con Amalia, de José Mármol, (1817-1871), cuya primera parte apareció en 1851 y la segunda en 1855 . No obstante, en ella hay una tentativa de caracterizar al dictador Juan Manuel de Rosas, a partir de los textos producidos por el contexto de la dictadura. A partir de Amalia se abre una serie que llega hasta novelas de nuestro tiempo, como las escritas sobre la dictadura de Pérez Jiménez: Se llamaba S.N. (1964) de José Vicente Abreu, o La muerte de Honorio (1963) de Miguel Otero Silva; o bien, del mismo Otero Silva, su novela Fiebre (1939) que, junto con Puros hombres (1938), de Antonio Arráiz, se remiten a la situación represiva durante la dictadura de Juan Vicente Gómez. En tónica similar, aunque elaboradas con técnicas muy diferentes, se pueden señalar $E l$ coronel no tiene quien le escriba (1962) y La mala hora (1963) de Gabriel García Márquez, autor en cuyas obras ya no hay una periodización histórica precisable con exactitud, porque el propio objeto la disuelve como atmósfera sólo delineada a base de indicios que marcan la represión y la violencia, $\tan$ innominadas como los pasquines y la resistencia social a los mecanisnos opresivos. En la serie es igualmente ubicable Conversación en la catedral (1969) de Mario Vargas Llosa, que busca autopsiar el sistema funcional de la dictadura de Odría, a través de las vidas privadas de unos interlocutores. En todas ellas está, pues, de manera más o menos explícita según las técnicas y escrituras de cada narrador, la atmósfera, la situación de una dictadura, pero no se perfila aún el dictador.

La sub-clase de novelas de dictadores es más característica de la narrativa del siglo XX. Son novelas que se circunscriben al objeto singularizado. Desde Tirano Banderas (1926) de Valle Inclán hasta El señor Presidente (1946) de Miguel Angel Asturias, se va constituyendo el ciclo de textos que, sin embargo, por su lenguaje, la acumulación anecdótica, las referencias históricas, pueden remitir a un dictador individualizado, circunscrito a un país, dentro de una época. La última del tipo, con características nuevas, ha sido Yo El Supremo (1974) de Augusto Roa Bastos. Todas podrían valorarse como casos particulares de novelas centradas en un personaje, con una especialidad y una especificidad temporal más o menos definidas. 
En medio de las dos sub-clases anteriores (novelas de dictaduras, novelas de un dictador) quedaba otra posibilidad de novelización, una rendija retadora, capaz de permitir la construcción, abstractivamente, de un objeto narrativo a partir del objeto dictador, como concepto extensivo a toda una clase. Una novela capaz de condensar en su universo narrativo la doble red verbal de atributos: magnificadores (negadores)/denostadores (afirmadores) del dictador, más allá de su realización casuística. Esa novela impondría al narrador una serie de nuevos problemas:

1.- Debía ser una novela capaz de construir ficcionalmente (o reconstruir en un segundo discurso) el objeto-dictador sobre una concentración de todos los atributos relevantes de la clase.

2.- Lo anterior suponía, a la vez, no limitarse a un caso individual sino abarcar la clase de objetos incorporables en ella. En lugar de la novela de un dictador, la novela de todos los dictadores habidos, al menos en el contexto hispanoamericano. Esto suponía, entonces, la pérdida de identidad del personaje.

3. - Para lograrlo, era necesario romper una periodización histórica específica y ampliar el universo ficcional a la historia continental de los dictadores de ambos siglos (XIX-XX). Así, la distancia con la biografía y la historia política de individualidades, se logra en función de una mayor efectividad estética, pero también política. Esto no significa que el texto se convierta en una novela anti-histórica, sino des-historizada (a-histórica), porque de hecho se cierra la posibilidad de la novela histórica, o de la biografía novelada.

4.- Por último, este tipo de objeto narrativo imponía construir una especialidad ficcional sobre base de una serie de indicios geográficos sueltos, o más bien disueltos en la masa narrativa, localizables sólo parcialmente en un contexto nacional. Así queda rota la ambientación descriptiva, limitadora, para dejar paso a una universalización del discurso cuyo espacio es sólo edificado en el texto mismo y es percibido por el lector de modo diferente según su marco histórico de referencia.

Creemos que a este último corresponde el grupo iniciado a partir de $E l$ gran Burundú Burundá ha muerto (1952) de Jorge Zalamea, subtitulado por su autor como "poema satírico"; alcanza momentos excepcionales a través de dos obras: El recurso del método (1974) de Alejo Carpentier y El otoño del patriarca (1975) de Gabriel García Márquez. 


\section{EL RECURSO DEL MÉTODO, NOVELA DE "EL DICTADOR" LATINOAMERICANO}

\section{1. - EL PUNTO DE VISTA.}

El recurso del método está construido a partir de un doble punto de vista: $a$ ) el de un narrador de tercera persona y $b$ ) el del propio Primer Magistrado, quien narra en primera persona. Se trata de una típica omniscencia selectiva.

Esta doble visión permite una perspectiva de contraste entre la imagen que del objeto dictatorial tienen el Primer Magistrado y su entorno, y la que sus adversarios van construyendo en la novela.

El narrador de tercera persona - no identificable con el novelista evalúa irónicamente el objeto desde la perspectiva de un testigo que acompaña el desarrollo de las acciones. Es co-partícipe en la construcción del objeto narrativo dentro del texto mismo.

El narrador de primera persona es también sujeto portador del objeto dictatorial. Se auto-evalúa y califica su entorno.

Ambas perspectivas conjugan la discursividad integral y estratifican el texto en dos planos expresivos.

\section{2. - EL OBJETO DICTADOR.}

El objeto dictatorial está concebido narrativamente como una síntesis cualitativa de dictadores latinoamericanos, con énfasis en sus exponentes históricos de finales del siglo pasado y del presente; aunque el autor haya tratado de circunscribir la cronología abarcada por su novela en un período que va desde 1913 hasta 1972, su intencionalidad queda rebasada por los contextos mismos que abarcan la totalidad del objeto, cuya clase, en expresión del propio autor, está integrada en Hispanoamérica por más de mil individuos. ${ }^{33}$ En todo caso es la imagen de un dictador moderno

33 En una entrevista concedida por Carpentier a Miguel F. Roa, de Prensa Latina, el novelista revela datos de interés sobre este aspecto. (Citamos la versión reproducida en Letras Nuevas. Caracas, enero-marzo 1975, № 12). Sobre la cifra de dictadores, dice: “... en fin de cuentas, entre esos que llamaba Miranda, precursor de nuestra independencia, "bochinches y cuartelazos", más de mil en la totalidad del hemisferio insular y de tierra firme, en un algo más de siglo y medio" (p. 11).- En cuanto a la presunta delimitación cronológica, señala: "La acción de mi novela comienza muy exactamente en el año 1913, pero su acción se prolonga concretamente con una sincronización de hechos y de épocas hasta el año 1927 , con alusión a varios acontecimientos históricos. Pero después hay un período que va conduciendo a mi personaje central hacia los años treinta, cuarenta, con un epílogo de dos páginas que se titula: "1972". (p. 12). 
elevado a condición narrativa de modelo donde convergen los atributos de una totalidad histórica. Desde el punto de vista de las referencias espaciales y contextuales el ámbito dictatorial está alejado aparentemente del que correspondería por indicios de época a dictadores como el Doctor Francia, Juan Manuel de Rosas, etc. Se acerca más a un lindero hipotético que pudiera fijarse hacia 1870 cuando está en auge la autocracia venezolana de Guzmán Blanco, finaliza la tremenda era de Melgarejo en Bolivia (1871), se inicia en México la de Porfirio Díaz (1876). El final de la novela alude a la caída de Gerardo Machado (1933), pero la muerte del dictador en París y su sepulcro en Mont parnasse remiten a la de Porfirio Díaz (1915) y los indicios del maletín y la huida del dictador aluden a la espectacular fuga de Pérez Jiménez (1958).

El objeto dictatorial se muestra significado - en cuanto signo- por un sujeto carente de identidad personal, de nombre propio. Su designación permanente es la de Primer Magistrado. Es una imagen múltiple, no relacionable completamente con ninguno de los individuos aislados que integran la clase de objetos 'dictador' en el devenir histórico. No hay entonces un referente material - sólo el concepto, la "imagen mental" hacia donde pudiera orientarse el lector para identificar al personaje. Los dos narradores - el de tercera persona y la primera persona dictatorial aluden frecuentemente a incidencias y atributos de otros dictadores señalados por sus nombres, que accionalmente constituyen falsos indicios, paralelismos o redundancias implícitas en el objeto, cuya funcionalidad, al explicitarse en la escritura, es la de lograr la desconcentración del lector en su búsqueda de una identidad homologable con un ejemplar dictatorial singularizado.

Uno de los pocos nombres omitidos es Rafael Leonidas Trujillo quien, sin embargo, aporta a la materia del texto (forma del contenido narrativo) buena cantidad de anécdotas y componentes básicos para el entorno familiar: los hijos. ${ }^{34}$ Porfirio Díaz (México), Juan Vicente Gómez (Venezuela) Gerardo Machado (Cuba), Estrada Cabrera (Guatemala), todos dictadores del siglo XX, junto a José Gaspar Francia (Paraguay - s. $\mathrm{XIX)}$ son mencionados por sus nombres como individuos que aparentemente difieren - al nombrarlos en el discurso como personas distintas del Primer Magistrado - del objeto, pero convergen en él como rasgos o elementos del modelo dictatorial.

Los falsos indicios señalan que el Primer Magistrado hace escala en La Habana, cuando viene rumbo a su país para sofocar la rebelión de

34 Especialmente Radamés Trujillo, coincide con el hijo del Primer Magistrado: deportista, desertor de West-Point, play-boy, muerto en carrera automovilística. 
Galván. ${ }^{35}$ Ello descarta la identificación con Gerardo Machado. En La Habana se entera por la prensa sobre la rebelión contra Porfirio Díaz, que es una "revolución de verdad" (p. 43). Respecto a Juan Vicente Gómez, hay varias frases que aluden a los "chácharos andinos"; además, el dictador venezolano resulta compadre del Primer Magistrado, a quien aconseja neutralidad durante la Primera Guerra Mundial. ${ }^{36}$ El caballo Holofernes y la Mayorala Elmira lo acercan a Mariano Melgarejo. ${ }^{37}$

Rasgos que lo aproximarían parcialmente con un "déspota ilustrado" crean cierto parentesco con José Gaspar Francia, García Moreno y Guzmán Blanco, aunque el propio Carpentier, en su entrevista - engloba también en este sub-grupo a Estrada Cabrera. ${ }^{38}$ Este último, en la novela es calificado como "su amigo" y hombre inclinado a cierto fasto dilettante.

Las autodesignaciones magnificadoras (ocultadoras o negadoras) que ideologizan al objeto dictatorial son Presidente, Presidente Constitucional y, sobre todos, Primer Magistrado, epíteto que lo acompaña, como si fuera su propio nombre, hasta el final de la novela, cuando él mismo se autodefine como el Ex. ${ }^{39}$ El narrador omnisciente adopta las mismas

35 La Habana está en Carnaval. E1 Magistrado comenta: “ ¡Ciudad más ruidosa! (...) Al lado de esto nuestra capital es un convento de monjas". (p. 44). Enterado del estallido de la Revolución Mexicana, indica que sus ecos están siendo voceados "en nuestro país", por Galván. (p. 43). Estas y todas las citas restantes de la novela, remiten a la $2 a$ ed. México, Siglo $X X I, 1974$.

36 "El conflicto no era de hoy. Hacía medio siglo que estos andinos venían jodiendo la paciencia con sus marchas sobre la capital y sus caudillos". (p. 59). En París, El Primer Magistrado “... había recibido de su compadre Juan Vicente Gómez, General de generales adictos al bigote kaiseriano y al monóculo calado - por vía confidencial verbal, pues el dictador venezolano temía que se mofaran de su ortografia - el sabio consejo de mantenerse al margen de todo, pues "chiquito que se mete en pleito de grandes siempre sale fregado". (p. 113).

37 La Mayorala Elmira tiene claras afinidades con la chola Juana Sánchez, - salvo su recato moral revelado en París - la famosa amante de Melgarejo. En la novela se habla de alzamientos "a la boliviana" (p. 31) y el Primer Magistrado es dueño de un caballo: "Holofernes", que tomaba cerveza como la famosa bestia del "Benemérito de la Patria" de Bolivia.

38 En su entrevista para Prensa Latina, Carpentier establece tres tipos de dictadores: 1) el "general de pistola y fusta", llamado por Alcides Arguedas "caudillo bárbaro"; 2) "el dictador a secas" y 3) el "tirano ilustrado". "El tirano ilustrado es Estrada Cabrera en Guatemala, que teniendo las cárceles llenas de gente, erigía nada menos que un templo a Minerva ... El tirano ilustrado es el Guzmán Blanco que tiene cierta cultura, que lee libros famosos, tiene casa en París, viaja, vuelve, opina, etc. y en fin de cuentas por otras manos (...) comete los mismos atropellos del general de pistola o del dictador a secas, que no sabe ni por qué está en el poder". (p. 12).

39 Peralta reitera: "Como Mi Presidente no hay dos" (pp. 118, 219). El Ilustre Académico francés lo llama: "Conductor de Pueblos", "Gran Capitán" (p. 98). El dictador rechaza el tratamiento de General (p. 54) y desconfía de los elogios (122, 129, 137, 238-239). En América, "... a medida que me henchía del aire de mi aire, me iba haciendo más Presidente" (p. 46). Para las compañías imperialistas es el "Presidente Constitucional de la República" (p. 37). 
designaciones y a veces las ironiza por inversión significativa, o las cambia por El Príncipe, la Alta Sombra y El Patriarca. 40 La designación tirano aparece como uso negativo o "figurativo", en la ironía de Gabriel D'Annunzio, que en París es amigo y usufructurario del Primer Magistrado. 41 Otras veces, en las denostaciones, por extensión es comparado con Calígula, Tiberio o su caballo-cónsul Incitato. 42

En las justificaciones de la dictadura, sus masacres y represiones, aparecen otros epítetos que lo van modelando positiva o negativamente. Así, después de la derrota de Galván - el hombre que tantas veces lo había exaltado como "benefactor-providencia" (p. 31) - será llamado "Carnicero de Nueva Córdoba". ${ }^{43}$ Y cuando Hoffmann termina sumergido en las tembladeras del Sur, el Congreso magnifica al Primer Magistrado en su regreso triunfal como "Benemérito de la Patria y Pacificador" (p. 137). Durante el auge económico se convierte en edificador de una ciudad remozada de rascacielos, con su Capitolio de mármol, pero también como constructor de prisiones "modelos" y se auto-escarnece llamándose "El Primer Hotelero de la República". ${ }^{44}$ Cuando se opera su aislamiento

La auto-degradación comienza con la alegoría de las estatuas; una de ellas, la ecuestre, muestra el caballo "privado de Quien" (292). Convertido en mercancía de contrabando, refugiado en el Consulado norteamericano, después de ser "amo de hombres, destinos y haciendas", llora sobre el diccionario que ha omitido su nombre (293). En su retiro definitivo a París, "ahora se llamaba el Ex con crispada ironia". (297) o es llamado "mon père le Président" por Ofelia, a la que secundan sus amigos de orgía (303).

40 Una de las burlas del narrador de tercera persona es: "reposo hallaba el primer magistrado a la sombra de los cañones en flor" (146); "Patriarca de mieses y rebaños" (184-185); envuelto en su entorno de confidentes: “... eran Vigilantes, Observadores de Astutos, memorialistas de cuanto inventaban, urdían, tramaban, los mismos colaboradores, familiares o contertulios del Primer Magistrado, al favor de su Alta Sombra" (183).

41 D'Annunzio, por teléfono: "Ah, lo que no daría por tener los poderes de un tirano de América Latina y limpiar la Rue Geoffroy l'Asnier de malandrines y sacripantes como, en Nueva Córdoba había hecho el generoso amigo que ahora le hablaba". (...) El Magistrado “... no sabía cómo tomar lo de tirano, ya que el poeta solía usar un lenguaje 'imaginífico' y ambiguo.." (pp. 93-94). En París, derrotado, en uno de sus pleitos con Ofelia, ésta pensaba del 'papacito lindo': "Si se le devolvía la autoridad de otros días (...) si no se le cortaban las ínfulas, si no se le atajaban los impulsos, acabaría de tirano acá como lo había sido allá -, acostumbrado a ser tirano siempre". (303).

42 La hoja satírica de los partidarios de Luis Leoncio Martínez “... le calificaba en remedo y chunga, de 'Tiberio de zarzuela', 'Sátrapa de Tierras Calientes' ..." (p. 51). El proceso culmina en el diálogo con El Estudiante: "Y poniéndole una mano en el hombro: --Para tí, debo ser algo así como un Calígula... ¿no? - Más bien como el caballo de Calígula" (p. 243).

43 Según Le Matin de París (pp. 94-95). Más tarde el panfleto es reimpreso con las fotos de Mr. Garcin, en la cadena yanqui Randolph Hearst, cuando el dictador había caído y se entronizaba Luis Leoncio Martínez (p. 282).

44 "El Primer Magistrado se entregó con remozada energía - . . - a lo que habría de ser su gran obra de edificador..." (pp. 152-153). Peralta le habla de las "células marxistas". El responde: "Para células, las de la 'Prisión Modelo'. (...) 'Ya no bastan para meter tanta gente'. (Trataba de reir). '- Me he vuelto el primer hotelero de la Repúblicá (p. 224). 
progresivo dentro de la "isla del Palacio", termina auto-erigido en víctima, según se nos revela a través del diálogo con El Estudiante: "Hoy, oyéndote hablar, me di cuenta, de repente, de que soy el Primer Preso de la Nación. Si. No te sonrías". (p. 240).

Una vez diluida la imagen de un dictador sin identidad posible, en el objeto dinámico abstractivo de "el dictador", ideologizado sistemáticamente, éste asume toda la estructura de la historia narrativa como eje de las acciones lineales y progresivas, organizadas a su alrededor. La pérdida de identidad individual en el modelo se expresa dentro del texto a partir de un signo alegórico explícito: El Cónsul norteamericano, último denostador, en Puerto Araguato, le comenta: "Ahora esas estatuas suyas descansarán en el fondo del mar; (...) Y allá por el año 2500 ó 3000 las encontrará la pala de una draga, devolviéndolas a la luz. (...) Pasará lo mismo que con las esculturas romanas de mala época que pueden verse en muchos museos: sólo se sabe de ellas que son imágenes de Un Gladiador, Un Patricio, Un Centurión. Los nombres se perdieron. En el caso suyo se dirá: "Busto, estatua, de Un Dictador. Fueron tantos y serán tantos todavía, en este hemisferio, que el nombre será lo de menos". (p. 293). Esta alegoría del objeto carente de identidad individual lo erige en núcleo auto-rechazado por su portador, y a la vez en síntesis de la clase dictatorial. No es casual que sea el epíteto que más ofendía al Primer Magistrado, lo mismo que las comparaciones y paralelos con la serie de dictadores con nombres propios a los que continuanente es igualado en la denostación escrita, como se ha visto. 45

\section{3.- EL "MODELO" DICTATORIAL}

El objeto abstractivo del dictador en El recurso del método asume un carácter de meta-objeto semiótico. Es decir, de modelo. ${ }^{46}$ No sólo abarca

45 La resistencia clandestina, sintetizada simbólicamente en El Estudiante, con las hojas impresas y anónimas, cambia el lenguaje denostativo por la definición del objeto dictador: "No se le insultaba ya a la criolla, en jerga de solar y conventillo, con retruécanos y chistes de fácil invención, como antes se hacía, sino que, definiéndosele como Dictador (más le hería esa palabra que cualquier epíteto soez, cualquier intraducible remoquete, porque era moneda de enojoso curso en el extranjero - y, sobre todo, en Francia)". (p. 135).

Perdido el apoyo imperialista, "Una mañana, la noticia corrió de boca a oídos: en largo editorial, el especialista de asuntos latinoamericanos del New York Times hacía un implacable análisis de nuestra bancarrota, hablaba de represiones policiales y de torturas (...) recordando que el Primer Magistrado, puesto en la categoría de los Rosas, del Doctor Francia - quien fuera Dictador Vitalicio del Paraguay -, Porfirio Diaz, Estrada Cabrera en Guatemala, y Juan Vicente Gómez, de Venezuela - como quien hubiese hablado de Luis de Francia o Catalina de Rusia -, llevaba cerca de veinte años en el poder". (p. 217).

46 Siguiendo la definción de Bense: "Modelo es un concepto semiótico. Todo modelo tiene un carácter de signo: es un meta-objeto que hace referencia a un objeto o a un sistema de objetos al representarlos". (La Semiótica. Guía alfabética, p. 105). 
la clase de objetos dictatoriales, como interpretante del concepto ("objeto mental") dictador, sino que, además, el sentido total del objeto narrativo hay que buscarlo en la serie de los dictadores latinoamericanos y no en un dictador. Revela nuevamente la presencia de los sistemas discursivos enunciados en la parte teórica: magnificadores (negadores) / denostadores (afirmadores), cuyas lexías se han señalado en el desarrollo del aspecto anterior.

Además, este modelo engloba funcionalmente la dicotomía de la estructura misma del poder: dictadura/democracia, también mediante abstracciones conceptuales, ${ }^{47}$ que obligan a variar no sólo la retórica tipificadora del objeto abstractivo dictador ${ }^{48}$ sino que introduce un doble sistema ideológico de contradicciones: capitalismo (imperialismo) / socialismo, cuyas presencias se aproximan - pero no se confunden - en su funcionalidad opositora contra el objeto central ("dictador"), a lo largo de la novela. ${ }^{49}$ En este sentido se establece una relación compleja formada por los siguientes términos:

$\begin{aligned} & \text { Capitalismo }(\text { imperialismo })=\text { Dictador } / \text { Gobernante Democrático } \\ & (\text { Primer Magistrado) } / \text { Luis Leoncio Martínez }\end{aligned}$
$\begin{aligned} & \text { Socialismo }=\text { El Estudiante opuesto a } \\ & (\text { Revolución) }\end{aligned}$
$\begin{aligned} & \text { Dictador (aliado con Martínez) } \\ & \text { Democracia (opuesto a Martínez) }\end{aligned}$

47 Esta diconomía se expresa en la novela por la oposición Luis Leoncio Martínez/Primer Magistrado. El dictador ridiculiza al primero por frases evaluativas como "teósofo anarquista" (p. 50-51), "utopista vegetariano" (p. 72). A la inversa, los manifiestos opositores atribuidos a Martínez, llaman al dictador: "Presidente Procónsul", llegado al poder por un golpe de Estado, reelecto por sobre la Constitución, etc., (p. 50). Cuando Martínez se convierte para el imperialismo en "Hombre Providencial" (p. 250), la contrastación remite a la oposición de los dos sistemas en estas designaciones opuestas por su sentido: "ellos hablan de Defender la Democracia; nosotros (el dictador y su entorno) de Defender el Orden Establecido". (p. 251). Ambos sistemas, en la praxis narrativa, se homologan en el argumento de legalidad "constitucional" y en la alternancia como instrumentos del imperialismo (pp. 269270).

48 "Cien veces contrariadas por sus actos, esas palabras habian pasado del ágora al diccionario, de la encendida catilinaria al repertorio de las retóricas, de la elocuencia oportuna al desván de los trastos - vaciadas de sentido, secas, yermas, inutilizables. Pilares de sus grandes discursos políticos habían sido, durante años, los términos de Libertad, Lealtad, Independencia, Soberania, Honor Nacional, Sagrados Principios, Legítimos Derechos, Conciencia Cívica, Fidelidad a nuestras Tradiciones, Misión Histórica, Deberes-para-con-laPatria, etc". (p. 122).

49 La burguesía imperialista y la nacional pro-imperialista se expresan como imagen, asi: “junto a la isla del Palacio, otra isla - sumamente cercana y sin embargo intocable - había nacido en la ciudad: isla amarilla, demasiado recargada de molduras y labrados - un plateresco pasado por California - ... Y esa isla se centraba en el American Club". (pp. 248249) Son las "fuerzas vivas" que apoyan a Luis Leoncio Martínez, como solución a la crisis de 
Las oposiciones entre Dictador/democracia (gobernante "democrático") son de tipo formal, pero ambos se homologan como signos expresivos de mediatización imperialista. Democracia/Revolución se oponen en términos idénticos, aunque coinciden momentáneamente como opositores del Dictador.

Al signo alegórico, carente de nombre propio del Dictador (Primer Magistrado) le corresponde un máximo oponente de sentido contrario, pero de igual estructura narrativa globalizadora: El Estudiante. Así, la oposición ideológica más profunda es la de dos objetos conceptuales abstractivos. El Estudiante apenas se identifica vagamente como "un tal Alvarez", pero su validez artística está en cuanto se erige alegóricamente como el modelo de oposición revolucionaria que reemplaza a "los estudiantes", "La Universidad", "los discípulos de Luis Leoncio Martínez". ${ }^{50}$

El desgaste de la retórica dictatorial se intensifica diacrónicamente según va aumentando el deterioro del dictador como individuo. ${ }^{51}$ La sustitución

violencia que se da en el otro término ideológico de la oposición al dictador: "anarcosindicalismo" (pp. 99 y 179), marxismo que para el dictador es algo ignorado pero inquietante: "a mí no se me tumba con ecuaciones" (p. 189). Otros indicios son la persecución a la literatura "roja" (pp. 178-179, 181, 187), las "ideologías disolventes" (167) el "oro de Moscú" (226-227). Todo le resulta materia de burla al magistrado, hasta que el socialisno insurgente se tangibiliza, primero como "un algo" invisible, luego como resistencia revolucionaria, como denuncia doctrinaria en el periódico Liberación, y la gradación llega a climax en su enfrentamiento con El Estudiante, o con la certidumbre de la palabra C-O-M-UN-I-S-M-O (p. 186), las huelgas obreras; (p. 222-223), finalmente el pánico y la caída con la huelga general, donde los polos de la oposición (democracia y socialismo) coinciden como táctica contra el dictador. Ambos términos, democracia/socialismo, mantienen sin embargo su distancia expresiva en el desarrollo accional de la novela.

50 "No eran muchos, por suerte, los partidarios de esa doctrina (marxista) sin porvenir, ajena a nuestras costumbres - en todo caso sus actividades no habían sido muy visibles hasta ahora -, pero ya que se la consideraba, de pronto, como un motor posible, surgía ante los presentes la desléda figura de un joven de apellido Alvarez, Alvaro o Alvarado - (...) - más conocido por El Estudiante" (186). Su tarea como organizador de las luchas obreras se hace ostensible (223-224) hasta convertirse en la pesadilla esencial del dictador: "se nos está volviendo mito" (230-231), "no quiero mitos". "Nada camina tanto en este Continente como un mito" (232). El enfrentamiento de los dos mitos, Estudiante/Dictador proporciona una de las claves de la escritura narrativa, a través de contrapuntos de diálogos/monólogos entre ambos; nos referimos a la construcción triádica de lexias referidas a un mismo objeto: Estudiante $=$ Débil, Soterrado, Utopista $/$ Dictador $=$ Amo, Investido, Inamovible. (235). Es una modalidad expresiva que luego reaparece como una constante en las deshistorizaciones y desespacializaciones, como marca de la intención globalizadora.

51) Termina completamente desinflada en el diálogo con El Estudiante, primero por las tríadas contrapuestas. El Estudiante ve al Dictador: Poderoso, Capitalista, Patrón; a la inversa, el Dictador lo ve: Doctor Boloñés, Turlupino, Matamoros. Las visiones opuestas se condensan en: Tirano Clásico/Arcángel que fuimos todos. (234-235).

El Dictador toma conciencia de que al convertir sus monólogos en enunciados dirigidos al Estudiante, su conducta debe ser: “... no valerse del estilo frondoso de Plegaria en el 
del dictador por un gobernante "democrático" (heredero de epítetos análogos de magnificación, ineficaz en la transformación del status del país abstracto), muestra otra dimensión del problema político, pertinente a la narratividad del modelo. El sustitutivo democrático resulta igualmente debelado en sus ideologizaciones, tanto por el Dictador como por El Estudiante. ${ }^{52}$ Por debajo del gran sarcasmo, hay, pues, una presentación del sentido integral (abstractivo) de las contradicciones políticas en la historia latinoamericana contemporánea.

\section{4.- EL ENTORNO}

\subsection{Entorno familiar.}

Este núcleo íntimo, de doble contexto - Francés y del "país" funciona semánticamente como un conjunto definidor de las modalidades del neo-riquismo, típico de los sistemas políticos tanto dictatoriales como democráticos: afrancesamiento, germanisno, pitiyanquismo, contagiados o interaccionados del grupo familiar al sistema social construido en la novela. Por contraste, el parroquianismo primitivo de alcohol, sexo y sacralizaciones. Los dos primeros - alcohol y sexo, significados en Ron Santa Inés/Mayorala Elmira, atraviesan todo el texto narrativo como indicadores de la relación Primer Magistrado y país que gobierna. Las sacralizaciones abarcan en una misma red significativa, la madre, la esposa del dictador y las vírgenes latinoamericanas, congregadas en una misma estructura de invocaciones. ${ }^{53}$

Ofelia "la Infanta", constituye el agente primordial del neo-riquismo afrancesado. La Mayorala, el provincianisno integral. Ambas, los residuos del entorno degradado que acompaña familiarmente al $E x$ hasta su muerte.

Acrópolis, que un joven de nueva generación hallaría ridículo, sin caer - extremo opuesto -en el vocabulario guarango y barriotero que lo encanallaba" (237). Al final, convertido en $E x$, le queda la nostalgia de su propia retórica.

52 En París, el Ex hojea la prensa de $s u$ patria, donde se habla de Luis Leoncio Martínez, "Saludado como Restaurador y Custodio de la Libertad" (319). Y cuando "Todos esperaban que hablara el Sabio de Nueva Córdoba" (320), la parodia del discurso de gobernante "democrático", mezcla a Platón con la General Motors, exalta "la inversión extranjera, en esta América transfigurada por la pujante Técnica que del Norte nos viene" y termina, con otro tipo de eufemismos, hablando del "ocaso de las dictaduras en este Continente, estableciendo una democracia auténtica y verdadera, donde habría libertad de acción sindical, siempre que ésta no rompiera con una necesaria armonía entre el Capital y el Trabajo". (320).

En París, El Estudiante refiere a Julio Antonio Mella: "Tumbamos a un dictador, pero sigue el mismo combate, puesto que los enemigos son los mismos. Bajó el telón sobre un primer acto que fue larguísimo. Ahora estanos en el segundo que, con otras decoraciones, y otras luces, se está pareciendo ya al primero". (326).

53 Estas vírgenes agrupadas funcionan lo mismo para distraer la atención política con un milagro (110-111), como para apoyar al dictador en el combate contra los insurrectos (125) o rodearlo en la hora de la soledad pre-mortal en París (334). 
Las iras de Ofelia son una de las pocas fuerzas que acallan al dictador, mientras lo es. Lo aislan y arrinconan más dentro de la derrota. La Infanta Ofelia finalmente hace concesiones al contexto de su tierra, por la cual siente subestimación expresa. La Mayorala, por el contrario, se aficiona momentáneamente a los vinos del Bois Charbons, pero mantiene el vínculo con "el país" a través de los contextos culinarios y de curandería en pleno París. En conjunto, ambas imprimen cierta distensión al objeto dictatorial abstracto.

\subsection{Entorno político.}

En la intención del novelista el entorno político, específicamente dictatorial, - que él llama "una corte" en la entrevista ${ }^{54}$ - funciona como emisor primordial de los epítetos magnificadores (negadores del objeto). 55 E1 entorno político se desdobla como la relación espacial de la novela. Hay un entorno parisino y otro en "el país". El primero señala con énfasis el oportunismo de la clase media "afrancesada" o francesa, que rodea y parasita a expensas del dictador en auge, lo desaira en los reveses de su furia represiva o en la caída. 56

El entorno local - "del país" - provee de justificaciones al sistema dictatorial. Progresivamente se va desintegrando al invertir sus funciones y tornarse en red de oponentes identificados por sus nombres. Sus acciones van dirigidas finalmente al deterioro y derrocamiento del dictador. Así ocurre con los cuartelazos del General Ataúlfo Galván y de Walter Hoffmann, en los cuales se expresan las dos modalidades caudillescas (Galván) y fascistas (Hoffmann) de los golpes militares, aparte de que en

54 La conciencia e intencionalidad del entorno la expresa Carpentier así: "Y, luego, todo aquel mundo de diplomáticos, embajadores, negociantes, gentes, etc., que rodean una corte porque hay que hablar de corte en este caso -, hasta el día en que le fallan los mecanismos y dejan caer al individuo que les sirvió sus intereses políticos y económicos". (Entrevista Letras Nuevas, p. 12).

55 “Mi Presidente" (según Peralta). "Mi General, señor General” repetido hasta por las ruedas del tren" (p. 54). “... generoso amigo, distinto de los tiranos" (D'Annunzio) (p. 93). “...conductor de pueblos, gran capitán” (el Académico francés, p. 98); "depositario de una patriarca sabiduría que todos le reconocían" (los diplomáticos latinoamericanos en París, pp. 116-117); "Pacificador, Benemérito de la Patria" (otorgados ambos por el Congreso, "las Fuerzas Vivas, el Obispo Metropolitano en su púlpito, los Auxiliares en otros, menos empinados, y la Prensa..." (p. 137).

56 Es desairado por todos, luego de la masacre de Nueva Córdoba, menos por el Ilustre Académico, a quien paga para que prepare la justificación de prensa sobre la "prosperidad del país" (pp. 93-ss).

Derrocado, siente que "París, para mí se había despoblado" (305); "Y pensaba yo amargamente, en el lamentable fin de Estrada Cabrera; en los muchos mandatarios arrastrados por las calles de sus capitales; en los expulsados y humillados como Porfirio Díaz; en los encallados en este país, tras de un largo poder, como Guzmán Blanco; en el mismo Rosas, de Argentina (...) cuya hija había abandonado al duro patriarca al llegarle el ocaso..." (p. 307). 
función del dictador mismo, le sirven como justificativos de su gobierno, prolongado en nombre de la "paz y prosperidad", la "salvaguarda del orden y la ley". Son casos muy distintos al de Miguel Estatua, el caudillo popular. Los "Segundos Federiquitos" son blanco de los denuestos del propio dictador contra su entorno. ${ }^{57}$

Caso especial es Peralta, cuya funcionalidad cambiante es también una condensación del Secretario Privado, del Hombre de Confianza. Alcahuete, mandadero, magnificador constante ("Mi Presidente"), peculador hábil, conspirador oculto y oportunista, rebasa el sistema dictatorial y se infiltra en el sustitutivo democrático, luego de ser el agente oculto del terrorismo dentro de Palacio (las bombas).

\section{5.- LA DESHISTORIZACIÓN}

La novela provoca dificultades al lector que se empeñe en precisar cronológicamente el "marco histórico". Ciertos indicios permiten, sin embargo, pensar en un período aproximado que iría desde 1890 hasta los años 30 del siglo XX. Sus demarcadores indiciales en el universo narrativo podrían ser: a) afrancesamiento y Modernisno literario; b) Primera Guerra Mundial (En América: germanismo vs arielismo: latinidad); c) política imperialista del Big Stick y primeras invasiones imperialistas a Santo Domingo: 1916 ; d) crisis económicas de los años 30 y vanguardias políticointelectuales.

Por contraste, hay numerosos indicios anacrónicos o acrónicos, que rompen la secuencia de acontecimientos históricos para acercarlos hacia nosotros, a nuestro tiempo (aparato represivo armado de metralletas, diafragma anticonceptivo, aerograma del dictador desde alta mar). Son falsos indicios imbricados con clara intención de transgredir la linearidad histórica. Lo mismo ocurre con la huelga general en una ciudad de rascacielos y teleféricos, indudablemente la Caracas de Pérez Jiménez (1958). ${ }^{58}$

57 Ataúlfo Galván: "chácharo bochinchero", "ostrogodo de sables y vainas" (p. 52); Walter Hoffman": "alma renegada, infame, hedionda" (118); "luteranos de mierda como Hoffman" (125); "el rebelde era vivo espejo de la barbarie prusiana" (127).

Entorno militar: "Segundos Federiquitos" (125, 135, 144, 248).

Entorno policial represivo: "ese cretino Jefe de la Policía Judicial" (162 y 220); “estos detectives de mierda" (187); " $Y$ esta policía nuestra, coño, entrenada en los Estados Unidos, y que no sirve para un carajo, como no sea para pegar a hombres amarrados, dar tortol y ahogar gente en bañaderas" (233).

$58 \mathrm{La}$ explosión de la arquitectura moderna (rascacielos) podría ser común a diversos países, además de la Caracas de concreto armado que Pérez Jiménez levantó a expensas de la demolición de nuestra escasa arquitectura tradicional. No obstante, la alusión a los teleféricos de la ciudad capital, sin duda alguna remiten a los trazados sobre El Avila, cuando el dictador venezolano construyó el Hotel Humboldt en la cima del monte. 
La acumulación y reordenamiento ficcional de acontecimientos "realmente históricos", remite a diversos contextos nacionales y no a un solo país o un solo período, sino a diversas repúblicas latinoamericanas en variadas épocas. Son justamente las realizaciones en la praxis narrativa de lo que Carpentier había llamado convivencia de épocas históricas diversas, que en América convergen en un instante. ${ }^{59}$ Así ocurre, por ejemplo, respecto al Palacio Presidencial construido con tezontle y azulejos mexicanos, las prisiones "panópticas" "modelo", el Capitolio ${ }^{60}$ inaugurado en el Centenario de la Independencia de México. La Colonia Olmedo formada por inmigrantes de la Selva Negra Alemana ${ }^{61}$, con su trencito de juguete de los años 80-90. La literatura "roja" perseguida con la misma ignorancia en tiempos de Gerardo Machado (Cuba) y de otros congéneres. ${ }^{62}$

Estos cambios de temporalidades marcadas por incidencias narrativas e indicios materiales entremezclados, dificultan si no imposibilitan la concreción histórica, en el sentido de una periodización estricta; en cambio, globalizan la historia latinoamericana en su sentido contextual de tiempos y espacios que coexisten en el universo narrativo, pero difieren más allá de él.

\section{6. - LA DESESPACIALIZACIÓN.}

Donde más se enfatiza la voluntad abstractiva dominante en la novela de 'el dictador' es en la red de falsos indicios dirigidos a presentar una geografía equívoca y la desespacialización se logra mediante la contigüidad

\footnotetext{
59 Es idea reiterada por él; expuesta inicialmente en su libro Tientos y diferencias (1964). Cf. particularmente la "Problemática de la actual novela latinoamericana" y "De lo real maravilloso americano". Tal vez el soporte teórico de El recurso del método, podría estar ahí. Por principio hay referencias a Melgarejo como "lo absurdo histórico", por su caballo Holofernes, bebedor de cerveza. (p. 127 en la la. ed. México, UNAM, 1964). En su concepción de los vaivenes contextuales, dice: "Ví la posibilidad de establecer ciertos sincronismos posibles, americanos, recurrentes, por encima del tiempo, relacionando esto con aquello, el ayer con el presente (p. 129).

60 El Palacio Presidencial podría ser, en efecto, el de México, Prisiones "panópticas se construyeron en Cuba (Isla de Pinos), Ecuador y Venezuela (La Rotunda). El Capitolio es el de la Cuba de Machado, pero se inaugura en el Centenario de la Independencia (¿de México?).

61 Por su descripción parece ser la Colonia Tovar (Venezuela) fundada por Páez, (184).

62 En la entrevista a Prensa Latina (Letras Nuevas), refiere las coincidencias extratemporales de un mismo hecho: la recolección de libros "rojos", en la Cuba de Machado y, "veinte años después, en un país de Centroamérica, se hizo exactamente igual, se recogieron los mismos libros que, en cierto modo, han sido quemados en las plazas públicas de un país de América del Sur". (Letras Nuevas, p.11).
} 
de referencias geográficas aparentemente exactas, incluso existentes en varias naciones, para construir un país innominado, al igual que el dictador. La capital, Nueva Córdoba, es una amasijo de rasgos de las que Carpentier ha definido como ciudades latinoamericanas "sin estilo". En nivel menor, ocurre algo semejante con Puerto Araguato.

\subsection{El país.}

Una vez suprimida la identidad onomástica, el país abstractivo es una suerte de modelo espacial donde se mueve el Primer Magistrado dentro de una toponimia sincrética e imprecisa.

Visto el país desde una perspectiva de distancia - París - es identificado a lo largo de toda la novela con una vaga referencia ubicativa: allá. Cuando el dictador está en él, combatiendo o gobernando, entonces se convierte en acá o aquí, formas con las cuales el dictador localizaba la capital francesa en las épocas de su permanencia en ella. Ahora, por inversión, desde el país, Francia es allá e, incluso, Europa es allá de allá.

Otras designaciones son "mi país", "nuestro país", "estas tierras del futuro", en la visión del Primer Magistrado. Para Ofelia es "ese país de mugre y grajo".

La división política es una composición amosaicada de la "loca geografía americana". En primer lugar, se divide en Provincias del Norte, de la Banda del Pacífico (p. 31) o de las costas del Atlántico, lo cual descarta la posibilidad de un territorio insular de dictadores: Cuba, Haití, República Dominicana. En las "tórridas tierras sureñas" (p. 127) se ubican las provincias llenas de Tembladeras (arenas movedizas) donde abundan las victoriarregias paraguayas (pp. 121 y 135). Estos últimos detalles excluyen a México y Centroamérica. Además, ocurre que los barcos norteamericanos están cerca de sus costas, realizando maniobras en el Caribe (p. 72) y hay páramos andinos con frailejones (Venezuela), en un país donde la United Fruit Company establece sus reinos sobre las costas del Pacífico (p. 33).

\subsection{La capital}

Nueva Córdoba es fundada en 1553. Tiene un Volcán Tutelar, antigua morada de los dioses; su arquitectura variable y complicada se parece a La Habana o a Caracas, con un Palacio de Gobierno mexicano y todo ello levantado sobre calles y avenidas que se llaman: San Juan de Letrán (México) Economía (La Habana), San Isidro, La Chayota (Caracas) y sus barrios marginales son a un tiempo Villas - miseria y favelas (brasileñas). Creemos suficiente la enumeración de muestra. 


\section{7.- INTENCIÓN GLOBALIZADORA.}

Si el país carece de una identidad de nombre y su ciudad lo tiene, pero es una combinatoria de ciudades, el Continente es "El otro Hemisferio", "este lado del Océano", o simplemente América, nuestra América, la América de Abajo, América Latina; también se procura la síntesis, la suma indicial a través de los reiterados contextos integrales sobre los que tanto ha insistido Carpentier como ensayista.

El recurso de las agrupaciones triádicas, que apuntábamos en 3. (El modelo dictatorial, nota 50), del léxico atraviesan la escritura de la novela como una sinfonía de polimorfismos referidos a alimentos, bebidas, atuendos, calzado, música e instrumentos musicales, matices étnicos, designaciones mixtas, fauna, celebraciones y fiestas típicas. Analizar todo este léxico, de abundancia enorme, fundamento dialectológico de la escritura barroca, conduciría a un interminable recuento. Resumimos apenas una muestra de tales recurrencias expresivas como una insistencia más en la idea de que el sentido abstractivo dominante en la novela es un sistema de construcciones que sólo convive en el texto a diversos niveles de su estratificación y se capta como una característica de diseño en el objeto narrativo. Las series de enumeraciones forman contigüidad textual; fuera del texto, son elementos aislados que están presentes en diferentes realidades nacionales, como objetos o como designaciones de ellos. Todos son la heterogeneidad diferencial de un Continente que, en su historia republicana de ciento cincuenta años, está identificado en una misma lucha contra la dependencia del imperialismo y padece los mismos instrumentos de dominio en el juego democracia/dictadura, con la sola y ejemplar excepción de la Cuba Socialista.

\section{8.- CONCLUSIONES}

Hemos querido constatar en la praxis de la novela una formulación teórica de los contextos dictatoriales de Hispanoamérica, sobre la base de una doble relación de lenguajes: el objeto-conceptual y verbal del dictador y el meta-objeto narrativo construido a partir del primero.

El análisis de las obras demuestra que las caracterizaciones teóricas del objeto se cumplen a partir de la conceptuación, independientemente de las perspectivas adoptadas por el novelista: novela de un dictador o novela de 'el dictador'.

La visión narrativa selecciona y combina un discurso previamente codificado (el lenguaje de la praxis dictatorial, la retórica de los dictadores: sus magnificadores y denostadores), como plano de contenido de la novela; a partir de él, la escritura novelística expresa las transformaciones que el 
CUADRO RESUMEN DE LOS POLIMORFISMOS LEXICOS GLOBALIZADORES. I

\begin{tabular}{|c|c|c|c|c|}
\hline CONTEXTO & DESIGNACIONES & PAÍS & CARACTERÍSTICAS & $\begin{array}{c}\text { LOCALIZACIÓN } \\
\text { PÁGS. }\end{array}$ \\
\hline ALIMENTOS & $\begin{array}{l}\text { tamales } \\
\text { hallacas }\end{array}$ & $\begin{array}{l}\text { México y } \\
\text { Centro } \\
\text { América } \\
\text { Venezuela }\end{array}$ & $\begin{array}{l}\text { Pastel envuelto en } \\
\text { hojas de maíz, re- } \\
\text { llenos variados. }\end{array}$ & p. 162 \\
\hline & $\begin{array}{l}\text { terneras en } \\
\text { parrilla y } \\
\text { elotes gratis }\end{array}$ & $\begin{array}{l}\text { Venezuela } \\
\text { México }\end{array}$ & $\begin{array}{l}\text { Carnes asadas } \\
\text { típicas del llano } \\
\text { Małz tierno }\end{array}$ & p. 170 \\
\hline ALIMENTOS & $\begin{array}{l}\text { tortillas de } \\
\text { maíz, } \\
\text { cuajadas para- } \\
\text { meras y carnes } \\
\text { enchiladas }\end{array}$ & $\begin{array}{l}\text { México y } \\
\text { C. América } \\
\text { Andes Ve- } \\
\text { nezuela } \\
\text { México y } \\
\text { C. América }\end{array}$ & $\begin{array}{l}\text { Pan de maíz } \\
\text { Queso fresco } \\
\text { envuelto en hojas } \\
\text { carnes picantes }\end{array}$ & $\begin{array}{r}\text { p. } 145 \\
\text { p. } 145 \text { y } 106 \\
\text { p. } 145\end{array}$ \\
\hline BEBIDAS & $\begin{array}{l}\text { botellas de } \\
\text { cachaza } \\
\text { tinajas de } \\
\text { guarapo } \\
\text { frascos de } \\
\text { charanda } \\
\text { minyules vera- } \\
\text { cruzanos, } \\
\text { ponches rosa- } \\
\text { dos de las } \\
\text { Antillas } \\
\text { mojitos cubanos }\end{array}$ & $\begin{array}{l}\text { Varios } \\
\text { Venezuela } \\
\text { México } \\
\text { México }\end{array}$ & $\begin{array}{l}\text { Aguardiente de } \\
\text { caña } \\
\text { Agua azucarada o } \\
\text { jugo de caña } \\
\text { Aguardiente de caña } \\
\text { bebidas mezcladas } \\
\text { (cocktails, dulces } \\
\text { a base de ron) }\end{array}$ & p. 66 y 207 \\
\hline ATUENDOS & $\begin{array}{l}\text { Hombres de } \\
\text { ruana y mujeres } \\
\text { de rebozo }\end{array}$ & $\begin{array}{l}\text { Colombia } \\
\text { Andes } \\
\text { México }\end{array}$ & $\begin{array}{l}\text { Capa de lana } \\
\text { para proteger- } \\
\text { se del frío }\end{array}$ & 73 \\
\hline CALZADOS & $\begin{array}{l}\text { alpargatas y } \\
\text { huaraches }\end{array}$ & $\begin{array}{l}\text { Venezuela } \\
\text { México } \\
\text { C. A. }\end{array}$ & $\begin{array}{l}\text { Calzado rústi- } \\
\text { co de suela y } \\
\text { manta tejida }\end{array}$ & $\begin{array}{r}63 \text { y } 79 \\
79\end{array}$ \\
\hline
\end{tabular}

(continua) 
(cont.) CUADRO RESUMEN I

\begin{tabular}{|c|c|c|c|c|}
\hline CONTEXTO & DESIGNACIONES & País & CARACTERISTICAS & $\begin{array}{l}\text { LOCALIZACIÓN } \\
\text { PÁGS. }\end{array}$ \\
\hline \multirow{4}{*}{$\begin{array}{l}\text { MUSICA E } \\
\text { INSTRU- } \\
\text { MENTOS } \\
\text { MUSICALES }\end{array}$} & $\begin{array}{l}\text { Negros que toca- } \\
\text { ban cumbia }\end{array}$ & Colombia & Danza costera & 164 \\
\hline & $\begin{array}{l}\text { decimistas y } \\
\text { payadores }\end{array}$ & $\begin{array}{l}\text { Cuba- } \\
\text { Antillas } \\
\text { Pampas } \\
\text { del Sur }\end{array}$ & $\begin{array}{l}\text { Improvisado- } \\
\text { res popula- } \\
\text { res }\end{array}$ & 198 \\
\hline & $\begin{array}{l}\text { Mitote } \\
\text { parranda } \\
\text { farra }\end{array}$ & $\begin{array}{l}\text { México y } \\
\text { Caribe } \\
\text { Venezuela } \\
\text { Argentina } \\
\text { y Plata }\end{array}$ & $\begin{array}{l}\text { Fiesta bohe- } \\
\text { mia con } \\
\text { música }\end{array}$ & 67 \\
\hline & $\begin{array}{l}\text { Porfía de } \\
\text { decimistas } \\
\text { música de } \\
\text { cuatro, } \\
\text { guitarra, } \\
\text { maracas, } \\
\text { furruco, } \\
\text { y tambor }\end{array}$ & $\begin{array}{l}\text { Cuba } \\
\text { Venezuela } \\
\text { varios } \\
\text { varios } \\
\text { Venezuela } \\
\text { varios }\end{array}$ & $\begin{array}{l}\text { Duelo entre } \\
\text { cantandores } \\
\text { improvisadores. } \\
\text { Guitarra peque- } \\
\text { ña de cuatro } \\
\text { cuerdas } \\
\text { tambor con asta } \\
\text { vibrante }\end{array}$ & 222 \\
\hline $\begin{array}{l}\text { MATICES } \\
\text { ETNICOS Y } \\
\text { SOCIALES }\end{array}$ & \multicolumn{2}{|c|}{$\begin{array}{l}\text { zambos, (varios), cholos } \\
\text { (Andes), atorrantes (Sur), } \\
\text { rotos (Chile), guajiros } \\
\text { (Cuba), léperos (México). }\end{array}$} & $\begin{array}{l}\text { Designaciones des- } \\
\text { pectivas de clases } \\
\text { populares y mezclas } \\
\text { étnicas del meztizaje. }\end{array}$ & 98 \\
\hline $\begin{array}{l}\text { DESIGNA- } \\
\text { CIONES } \\
\text { MIXTAS } \\
\text { (mezcla de } \\
\text { contextos) }\end{array}$ & $\begin{array}{l}\text { quenas, } \\
\text { guitarras, } \\
\text { ajiacos y } \\
\text { fejoadas } \\
\text { bohíos } \\
\text { liquiliques }\end{array}$ & $\begin{array}{l}\text { Andes } \\
\text { varios } \\
\text { Colombia } \\
\text { y Brasil } \\
\text { Caribe } \\
\text { Venezuela }\end{array}$ & $\begin{array}{l}\text { instru. mus. quechua } \\
\text { comidas con granos } \\
\text { vivienda popular } \\
\text { traje típico del } \\
\text { llanero }\end{array}$ & 102 \\
\hline FAUNA & $\begin{array}{l}\text { Buitres, auras } \\
\text { y zamuros }\end{array}$ & $\begin{array}{l}\text { varios } \\
\text { Venezuela }\end{array}$ & Aves de rapiña & $\begin{array}{r}76,82 \\
149\end{array}$ \\
\hline
\end{tabular}


sistema expresivo del objeto dictatorial proyecta en el objeto narrativo (meta-objeto del dictador) donde no sólo asume valor de objeto artístico, sino que recupera y amplía la posibilidad comunicativa del mensaje ideológico, en la medida que descubre las "ideologizaciones" utilizadas por las dictaduras en la praxis social.

La metodología combinada del análisis sémico y teórico político eran imprescindibles - a nuestro juicio - puesto que los objetos analizados comportan la doble significación, por lo demás común y extensible a cualquier objeto literario, considerado por definición como semióticamente heterogéneo.

La historización reelaborada con nuevos diseños narrativos - $\mathrm{Yo} E l$ Supremo - o la deshistorización globalizadora y abstractiva - El recurso del método - son dos modalidades de expresión artística - dos idiolectizaciones - cimentadas sobre una misma realidad: la realidad conceptual del dictador. Ni una ni otra eluden la realidad concreta latinoamericana, sino la reformulan a partir de una conceptuación - de una toma de conciencia -. Pero en lo literario la transforman y enriquecen así el lenguaje específico de la nueva narrativa de América Latina, por selección y combinación de signos que re-definen una materia (una temática asumida en tanto concepto) abordada desde otras perspectivas por novelas anteriores de las cuales se diferencian, en especial por la artisticidad; y con novelas posteriores con las cuales se homologan; particularmente la obra de Carpentier, que tiene antecedentes en la obra de Zalamea y analogías de intención globalizadora con El otoño del patriarca, de Gabriel García Márquez.

Las conclusiones siguen siendo aún provisionales, pues la misma ampliación del grupo novelístico tal vez modifique lo que hasta ahora nos parece confirmado. 
